\title{
COMMON COMPONENTS OF RISK AND UNCERTAINTY ATTITUDES ACROSS CONTEXTS AND DOMAINS: EVIDENCE FROM 30 COUNTRIES
}

\section{Ferdinand M. Vieider}

WZB Berlin Social Science Center,

Risk and Development Unit

\section{Ranoua Bouchouicha \\ Henley School of Business, \\ University of Reading}

\section{Rustamdjan Hakimov \\ WZB Berlin Social Science Center}

\author{
Mathieu Lefebvre \\ University of Montpellier 1, LAMETA
}

Thorsten Chmura
Nottingham University Business School

\author{
Michal Krawczyk \\ University of Warsaw
}

Peter Martinsson
University of Gothenburg

\begin{abstract}
Attitudes towards risk and uncertainty have been indicated to be highly context-dependent, and to be sensitive to the measurement technique employed. We present data collected in controlled experiments with 2,939 subjects in 30 countries measuring risk and uncertainty attitudes through incentivized measures as well as survey questions. Our data show clearly that measures correlate not only within decision contexts or measurement methods, but also across contexts and methods. This points to the existence of one underlying "risk preference", which influences attitudes independently of the measurement method or choice domain. We furthermore find that answers to a general and a financial survey question correlate with incentivized lottery choices in most countries. Incentivized and survey measures also correlate significantly between countries. This opens the possibility to conduct cultural comparisons on risk attitudes using survey instruments. (JEL: C90, D0, D81, J10)
\end{abstract}

The editor in charge of this paper was Stefano DellaVigna.

Acknowledgments: Ferdinand Vieider gratefully acknowledges generous financial support from the Excellence Initiative at the University of Munich and the WZB Berlin. The experiments in Costa Rica and Nicaragua were financed by Formas through the COMMONS program. The following people provided help with translations and in organizing and running the experiments: Clara Inés Villegas-Palacio, Marta Serra Garcia, Xiangdong Qin, Shuwen Li, Eva Xie, Jing Yu, Haileselassie Medhin, Yoshi Saijo, Takao Kusakawa, Frauke Mattison Thompson, Maria Angélica Naranjo, Francisco Alpizar, Phanith Chou, Phumsith Mahasuweerachai, Nghi Truong, Jiang Chong, Sunday Adewara, Martine Visser, Jolanda Ygosse Battisti, Michal Bauer, Jorge Dresdner, Hrvoje Stojic, Lachlan Deer, Diego Aycinena, Jorge Chang, Ashraf Eid, Lubomír Cingl, Alexis Belianin, Gautam Gupta, Olivier l'Haridon, and Daniel Schoch.

E-mail: fvieider@gmail.com (Vieider); mathieu.lefebvre@univ-montp1.fr (Lefebvre); r.bouchouicha@ reading.ac.uk (Bouchouicha); thorsten.chmura@nottingham.ac.uk (Chmura); rhakimov@wzb.eu (Hakimov); mkrawczyk@wne.uw.edu.pl (Krawczyk); peter.martinsson@economics.gu.se (Martinsson) 


\section{Motivation}

Risk and uncertainty attitudes occupy a central position if one wants to understand economic behavior. Attitudes towards risk and uncertainty determine not only investment behavior, but also job choices, education decisions, and social interactions. It thus seems desirable to be able to easily and cost-effectively measure such attitudes. Incentivized measures of risk attitudes are, however, difficult and costly to obtain, which limits their usefulness in large-scale investigations. Survey-based instruments have thus been developed to quickly and cheaply measure self-declared risk attitudes. It remains, however, largely unclear what such survey questions about risk attitudes measure exactly, and to what extent they reflect real decisions under risk and uncertainty.

A central issue in the discussion on the relative merit of survey measures concerns what is meant by risk. In the literature on decision making, this concept is usually identified with the case of given and objectively known probabilities, such as in roulette wheels (e.g., Abdellaoui, Vossmann, and Weber 2005; Wu and Gonzalez 1999). This concept, however, is too narrow for most real-world processes, which are better characterized as uncertainty, where the probabilities of the outcome generating processes are unknown or vague (Knight 1921). This case is often subsumed under the term "risk" at least in the popular terminology used by non-economists. Far from being a point of mere academic pedantry, this issue is central if one wants to explore the extent to which risk attitudes can be measured with simple survey questions on self-declared risk attitudes.

We address these questions using data from controlled experiments in 30 countries with 2,939 subjects. For each subject, we obtained certainty equivalents for 44 lotteries or prospects, which among other dimensions differed in the domain (gains and losses) and source of uncertainty (known and unknown probabilities). In addition, we elicited subjects' self-assessed risk attitudes, both in general and across a number of contexts, including, for example, sports, the health domain, and social risks.

We provide four main sets of results. First, we consider summary measures of the risk attitudes using a simple aggregate measure of decisions under risk and uncertainty, and for both gains and losses. We also summarize the responses to the survey questions. Second, we examine the individual correlations between the different incentivized measures and the survey questions to measure risk preferences separately for the 30 countries in our sample. Third, we examine the between-country correlations at the macroeconomic level. That is, we collapse the average measures of risk aversion at the country level and ask whether countries with higher levels of risk aversion according to revealed preference measures also have higher levels according to stated preference measures. Fourth, we examine the overall correlations between all the different measures across all countries, and we provide some evidence on the demographic determinants of risk aversion as captured by the different measures.

We find risk attitudes to be correlated across different decision contexts (general versus financial or occupational, etc.; Dohmen et al. 2011b), uncertainty sources (known and unknown probabilities; Abdellaoui et al. 2011), decision domains (gains 
versus losses; Einav et al. 2012), and elicitation methodologies (lottery choices and survey questions). In some cases the correlations are, however, only of moderate strength, thus also indicating important differences between the different methods and representations. In terms of correlations with losses, we find that uncertainty-averse choices in the gain domain predict uncertainty-averse choices in the loss domain, in agreement with the findings by Einav et al. (2012). We furthermore find that survey measures of uncertainty attitudes (henceforth understood to include risk as a special case) correlate with incentivized measures in the majority of countries, expanding the validation in Germany by (Dohmen et al. 2011b). We are the first to show significant between-country correlations of survey measures with incentivized measures. This opens the possibility of conducting country and cultural comparisons using survey instruments, which will make it possible to scale up such efforts without an explosion in costs.

This paper proceeds as follows. Section 2 describes the experimental setup and questions. Section 3 presents the results. Section 4 provides a discussion of the results and concludes the paper.

\section{Experimental Setup and Methods}

We present data on risk attitudes obtained from experiments in 30 countries on all continents except Antarctica. The countries were selected with an eye to diversification along several dimensions that were deemed potentially important for our study. These included inter alia geographic representation and spread, level of income per capita, and importance in economic and population terms. Beyond this, we faced some constraints in terms of countries in which we could find collaborators and universities willing to help us with the experiments, and had to exclude countries that would have proven too dangerous or otherwise unsuited for carrying out a controlled experiment. Figure 1 shows the countries that are included in our study.

A total of 2,939 subjects participated in controlled experimental sessions. Students were used so as to preserve comparability with typical results from experiments in the West, and since they were deemed more comparable across countries than other population groups. The downside is that this choice of subject pool results in a loss of representativeness. This may be worrying if selection into university changes systematically across countries. While there are certainly differences in selection into university, however, there is no systematic trend varying with important characteristics-we will return to this point in the discussion. Subjects were recruited at major public universities in the different countries, with a few exceptions where no collaborators at public universities could be found (Brazil, Malaysia, Saudi Arabia, and Tunisia). Care was taken to obtain a subject sample that was balanced in terms of sex and study major, although this was not always completely successful. For instance, in Saudi Arabia only males could be recruited because our male contact was not allowed to interact with female students. In universities with a standing subject pool we only recruited subjects who had participated in, at most, two experiments before, so that 


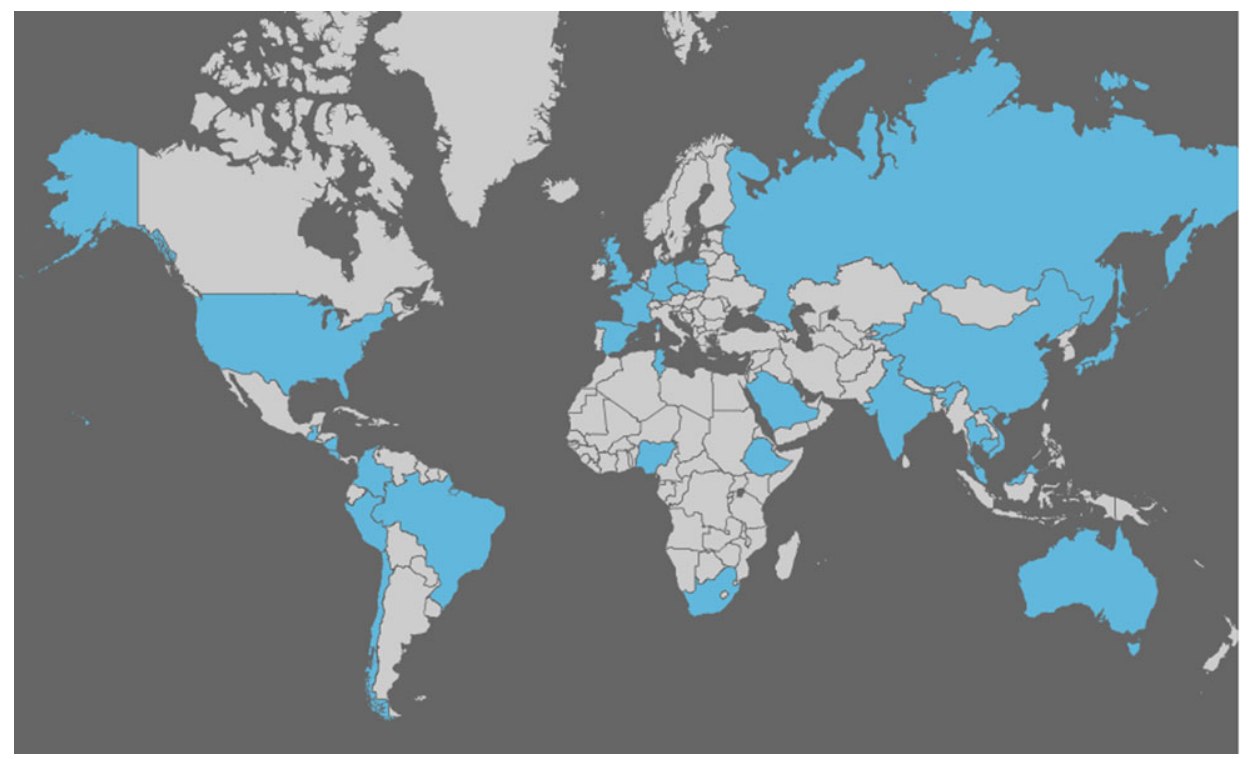

FIGURE 1. Countries included in the study (in blue).

they would be similar to subjects in developing countries for whom experiments were new. A table presenting an overview of the main subject characteristics country by country can be found in Appendix B.

All experiments were run between September 2011 and October 2012. Experiments across countries were kept as comparable as possible. The experiment was run in the teaching language of the university, since many countries included in the study are multilingual, so that the official teaching language is the only one shared by all students. Instructions were translated from English and back-translated into English by a different person (Brislin 1970). Differences were then eliminated by discussion. The payoffs were carefully converted using World Bank PPP data and then doublechecked using PPP conversion rates calculated from net wages of student assistants at the university where the experiments took place. Vieider (2012) tested explicitly whether small variations in payoffs in the order of $\pm 20 \%$ would make a difference in terms of measured risk attitudes and found none. Also, the experiment was run in two different cities in China-Beijing and Shanghai-and on two different campuses in Addis Ababa, Ethiopia, to determine whether differences found could be ascribed to differences in the subject pool, which would be troubling for an international comparison. No such differences were found once observable subject characteristics had been controlled for-for details of the results, see Vieider et al. (2014).

We elicited certainty equivalents for 44 binary prospects which differed by outcomes, probabilities, decision domain (gains versus losses), and source of uncertainty (known versus vague probabilities). We will henceforth represent a single prospect as $(x, p ; y)$, where $p$ is the probability of winning or losing $x, y$ obtains with 


\section{Decision 6}

\begin{tabular}{|c|c|c|c|}
\hline & Lottery & Sur & \\
\hline & $\mathrm{O}$ & 0 & $€ 20.50$ for sure \\
\hline & $\mathrm{O}$ & 0 & $€ 21.00$ for sure \\
\hline & $\mathrm{O}$ & 0 & $€ 21.50$ for sure \\
\hline & O & $\mathrm{O}$ & $€ 22.00$ for sure \\
\hline & $\mathrm{O}$ & 0 & $€ 22.50$ for sure \\
\hline & $\mathrm{O}$ & $\mathrm{O}$ & $€ 23.00$ for sure \\
\hline & $\mathrm{O}$ & 0 & $€ 23.50$ for sure \\
\hline & $\mathrm{O}$ & $\mathrm{O}$ & $€ 24.00$ for sure \\
\hline 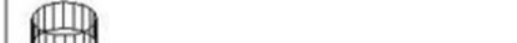 & 0 & $\mathrm{O}$ & $€ 24.50$ for sure \\
\hline & $\mathrm{O}$ & $\mathrm{O}$ & $€ 25.00$ for sure \\
\hline & O & $\mathrm{O}$ & $€ 25.50$ for sure \\
\hline & $\mathrm{O}$ & $\mathrm{O}$ & $€ 26.00$ for sure \\
\hline & 0 & 0 & $€ 26.50$ for sure \\
\hline Win $\boldsymbol{€} 30$ if one of the following balls is extracted: & o & $\mathrm{O}$ & $€ 27.00$ for sure \\
\hline & $\mathrm{O}$ & $\mathrm{O}$ & $€ 27.50$ for sure \\
\hline & $\mathrm{O}$ & $\mathrm{O}$ & $€ 28.00$ for sure \\
\hline Win $€ 20$ if one of the following balls is extracted: & $\mathrm{O}$ & $\mathrm{O}$ & $€ 28.50$ for sure \\
\hline & $\mathrm{O}$ & $\mathrm{O}$ & $€ 29.00$ for sure \\
\hline & $\mathrm{O}$ & $\mathrm{O}$ & $€ 29.50$ for sure \\
\hline
\end{tabular}

FIgURE 2. Example of choice list to elicit a CE.

a complementary probability $1-p$, and $|x|>|y|$. Values will be indicated in PPP euros-conversion factors are reported in Appendix B. Subjects were asked to make a choice between the prospect and different sure amounts of money contained between the two extreme outcomes of the prospect. For gains, the sure amounts increased from the lowest amount that could be won in the prospect to the highest. For losses, the sure amount decreased from the highest amount to the lowest. For gains, subjects will generally choose the prospect for small sure amounts and switch to preferring the sure amount as the latter gets larger (and vice versa for losses). The certainty equivalent $(C E)$ of a subject was encoded as the average of the last sure amount for which the prospect was chosen and the first sure amount chosen (vice versa for losses). It can serve as a direct measure of uncertainty aversion. An example of such a task for gains is displayed in Figure 2.

For gains, subjects were explained that "most likely, you will begin by choosing the lottery for small sure amounts, and at a certain point switch to the sure amount as the latter increases. If you do not want the lottery at all, you can choose to get the sure amount in the first row and then continue with the sure amount for all choices". Instructions for losses were similar but inverted, and can be found in the Online Appendix. One issue we faced was how to deal with multiple switching between the prospect and the sure amounts, which is sometimes observed in choice lists. We decided to exclude such behavior by telling subjects directly that "we are interested in 
the amount for which you will switch from preferring the lottery to preferring the sure amount". They were also instructed explicitly that they should not switch to and fro repeatedly, and that they could be excluded if they did so. As a consequence of this, no multiple switching occurred and nobody was excluded from the experiment. ${ }^{1}$

After completing all the tasks and filling in a questionnaire, one of the decisions was played out for real money. Every decision had the same probability of being extracted for real play. This provides incentives to respond according to one's true preferences and is the standard procedure in the literature (Baltussen et al. 2012; Bruhin, Fehr-Duda, and Epper 2010; Cubitt, Starmer, and Sugden 1998). The experiment took about 1 hour, and the expected payoff for a risk-neutral participant was about $€ 15$, with a minimum of $€ 4$ (the show-up fee) and a maximum of $€ 44$. The full instructions in English can be found in the Online Appendix. Instructions in several languages are available for download at www.ferdinandvieider.com/instructions. html.

The 44 tasks were distributed across different categories and domains. By decision domain we mean that choices were framed either as gains or as losses (plus one mixed prospect over gains and losses, which is not used here and which will not be mentioned further). Losses always came in a second part and took place from an endowment. This endowment was given conditional on the second part being selected for real play, and was equivalent to the highest loss of $€-20$ no matter what the selected choice. Etchart-Vincent and L'Haridon (2011) tested whether decisions from an endowment are different from decisions involving real losses and found no differences. In each of the two domains, we had tasks with known probabilities, which we call risky; and decisions involving unknown probabilities, which we call uncertain. Notice how the latter is different from ambiguity (Ellsberg 1961), which is given by the difference between choices under risk and under uncertainty, and which is not explicitly discussed here (see, e.g., Trautmann and Zeckhauser 2013, for a recent example of this use of terminology). The tasks were always kept in the same order, starting with risky gains and then uncertain gains; and in a second part, risky losses followed by uncertain losses. This was done so as to facilitate the logistics and avoid mix-ups. A large-scale pilot with 330 subjects showed that such a fixed ordering was less demanding for subjects, while not significantly affecting the measures used in this paper (results available upon request). A complete list of prospects can be found in Appendix A.

In the experiment, the urns were not called risky or uncertain, but rather "transparent" and "opaque". Concerning the risky urn, subjects simply learned that the urn contained exactly eight balls, numbered from 1 to 8 inclusive. About the uncertain urn they were told: "you cannot see what numbers the balls contained in the urn have.

1. Some scholars have argued that multiple switching may be indicative of indifference, and that it may thus be considered informative. It is, however, unclear how choice lists with multiple switches ought to be treated in the analysis. Indeed, the switching points have often been found to lie rather far apart, so that indifference is an unlikely explanation, with the more plausible explanation being that subjects who switched multiple times did not understand the task. This was also the reason why we tried to explain to subjects why they ought to switch only once, in addition to the prohibition of multiple switching. 
This means that you do not know the exact numbers that are present in that urn. All balls bear a number between 1 and 8 inclusive (have either 1, 2, 3, 4, 5, 6, 7, or 8 written on them), but it is possible that some numbers are absent from this urn while others occur repeatedly. Thus you do not know the exact composition of the urn." This implementation of uncertainty permits to center the uncertainty around a known probability distribution. In this sense, a prospect offering a given prize when a ball with the number 1 or 2 is extracted offers a vague probability interval that is centered on a probability of $2 / 8$. The vagueness derives from the fact that the probability may in reality be lower or higher than $2 / 8$. This design closely follows the procedures introduced and tested by Abdellaoui et al. (2011).

In addition to the incentivized tasks, subjects were asked a series of questions on their self-declared risk attitudes. These questions were taken from the German SocioEconomic Panel (SOEP). Subjects were asked about their "willingness to take risks in general", and had to indicate their answer on a scale ranging from 0 ("risk averse") to 10 ("fully prepared to take risks"). The full question read as follows:

How do you see yourself? Are you generally a person who is fully willing to take risks or do you try to avoid taking risks? Please tick a box on the scale below, where 0 means "risk averse" and 10 means "fully prepared to take risks":

\begin{tabular}{lllllllllll}
\hline $\begin{array}{l}\text { risk } \\
\text { averse }\end{array}$ & & & & & & & & & & \multicolumn{2}{c}{$\begin{array}{c}\text { fully prepared } \\
\text { to take risks }\end{array}$} \\
\hline 0 & 1 & 2 & 3 & 4 & 5 & 6 & 7 & 8 & 9 & 10 \\
$\mathrm{O}$ & $\mathrm{O}$ & $\mathrm{O}$ & $\mathrm{O}$ & $\mathrm{O}$ & $\mathrm{O}$ & $\mathrm{O}$ & $\mathrm{O}$ & $\mathrm{O}$ & $\mathrm{O}$ & $\mathrm{O}$ \\
\hline
\end{tabular}

The question was also asked for risk taking in specific contexts-driving, financial matters, the health domain, occupational risks, sports, and social risks (Dohmen et al 2010, 2011a, 2011b). These questions were added below the general question as follows:

People can behave differently in different situations. How would you rate your willingness to take risks in the following areas? How is it ...

\begin{tabular}{|c|c|c|c|c|c|c|c|c|c|c|c|}
\hline & \multicolumn{2}{|c|}{$\begin{array}{l}\text { risk } \\
\text { averse }\end{array}$} & \multirow[b]{2}{*}{2} & \multirow[b]{2}{*}{3} & \multirow[b]{2}{*}{4} & \multirow[b]{2}{*}{5} & \multirow[b]{2}{*}{6} & \multirow[b]{2}{*}{7} & \multicolumn{3}{|c|}{$\begin{array}{l}\text { fully prepared } \\
\text { to take risks }\end{array}$} \\
\hline & 0 & 1 & & & & & & & 8 & 9 & 10 \\
\hline —while driving? & $\mathrm{O}$ & $\mathrm{O}$ & $\mathrm{O}$ & $\mathrm{O}$ & $\mathrm{O}$ & $\mathrm{O}$ & $\mathrm{O}$ & $\mathrm{O}$ & $\mathrm{O}$ & $\mathrm{O}$ & $\mathrm{O}$ \\
\hline —in financial matters? & $\mathrm{O}$ & $\mathrm{O}$ & $\mathrm{O}$ & $\mathrm{O}$ & $\mathrm{O}$ & $\mathrm{O}$ & $\mathrm{O}$ & $\mathrm{O}$ & $\mathrm{O}$ & $\mathrm{O}$ & $\mathrm{O}$ \\
\hline —during leisure and sport? & $\mathrm{O}$ & $\mathrm{O}$ & $\mathrm{O}$ & $\mathrm{O}$ & $\mathrm{O}$ & $\mathrm{O}$ & $\mathrm{O}$ & $\mathrm{O}$ & $\mathrm{O}$ & $\mathrm{O}$ & $\mathrm{O}$ \\
\hline —in your occupation? & $\mathrm{O}$ & $\mathrm{O}$ & $\mathrm{O}$ & $\mathrm{O}$ & $\mathrm{O}$ & $\mathrm{O}$ & $\mathrm{O}$ & $\mathrm{O}$ & $\mathrm{O}$ & $\mathrm{O}$ & $\mathrm{O}$ \\
\hline —with your health? & $\mathrm{O}$ & $\mathrm{O}$ & $\mathrm{O}$ & $\mathrm{O}$ & $\mathrm{O}$ & $\mathrm{O}$ & $\mathrm{O}$ & $\mathrm{O}$ & $\mathrm{O}$ & $\mathrm{O}$ & $\mathrm{O}$ \\
\hline -your faith in other people? & $\mathrm{O}$ & $\mathrm{O}$ & $\mathrm{O}$ & $\mathrm{O}$ & $\mathrm{O}$ & $\mathrm{O}$ & $\mathrm{O}$ & $\mathrm{O}$ & $\mathrm{O}$ & $\mathrm{O}$ & $\mathrm{O}$ \\
\hline
\end{tabular}


These questions were always presented in the final questionnaire. They were presented towards the end of the questionnaire, after subjects had responded to a number of questions on demographics, as well as to some questions on cultural orientation. This makes it unlikely that subjects just answered in such a way as to match their responses to the incentivized measures. This is indeed also apparent from the choices themselves - see below for further evidence.

\section{Results}

We present the results in four parts. Section 3.1 discusses the construction of our main indices, and presents some general descriptive data. Section 3.2 correlates the survey measures with the incentivized data on risk taking within the 30 countries. In Section 3.3 we look into correlations of the different measures between countries, at the macroeconomic level. Section 3.4 examines correlations between different measures of uncertainty attitudes across all contexts and domains using the whole data set. It also explores the extent to which the different measures can be explained by the same independent variables in a regression analysis.

\subsection{Variable Construction and Descriptive Data}

Having observations for many different prospects, we need to aggregate these observations to make the analysis tractable. We thus aggregate our data throughout by decision domain (gains versus losses) and source of uncertainty (risk versus uncertainty proper), resulting in four different "revealed preference" measures (results for individual prospects are presented in the Online Appendix). The aggregation proceeds as follows. First, we construct a risk premium for every prospect, given by $E V-C E$, where $C E$ indicates the certainty equivalent and $E V$ the mathematical expectation of the prospect. Using a relative risk premium that is normalized by division by EV does not qualitatively affect our results- see the Online Appendix for an analysis using this alternative measure, as well as alternative aggregation techniques such as medians instead of means at the individual level.

Figure 3 shows the average risk premium, aggregated across different probabilities and outcome levels, by country. All Western countries are clearly risk averse on average as we would have expected (except for the United Kingdom, which constitutes an outlier ${ }^{2}$ ). Some countries such as Ethiopia, Nicaragua, and Peru, however, are significantly risk seeking. The exploration of characteristics underlying betweencountry differences is left for Section 3.4.

Figure 4 shows the risk premium for risky gains aggregated across all countries for different probability levels - that is, $(20, i / 8 ; 0), i=\{1, \ldots, 7\}$ (equivalent figures for

2. Our subject pool in the United Kingdom consisted of a majority of subjects with parents from Pakistan and India, which may provide an explanation for these findings. This will become clearer when looking at the general trends in what follows. 


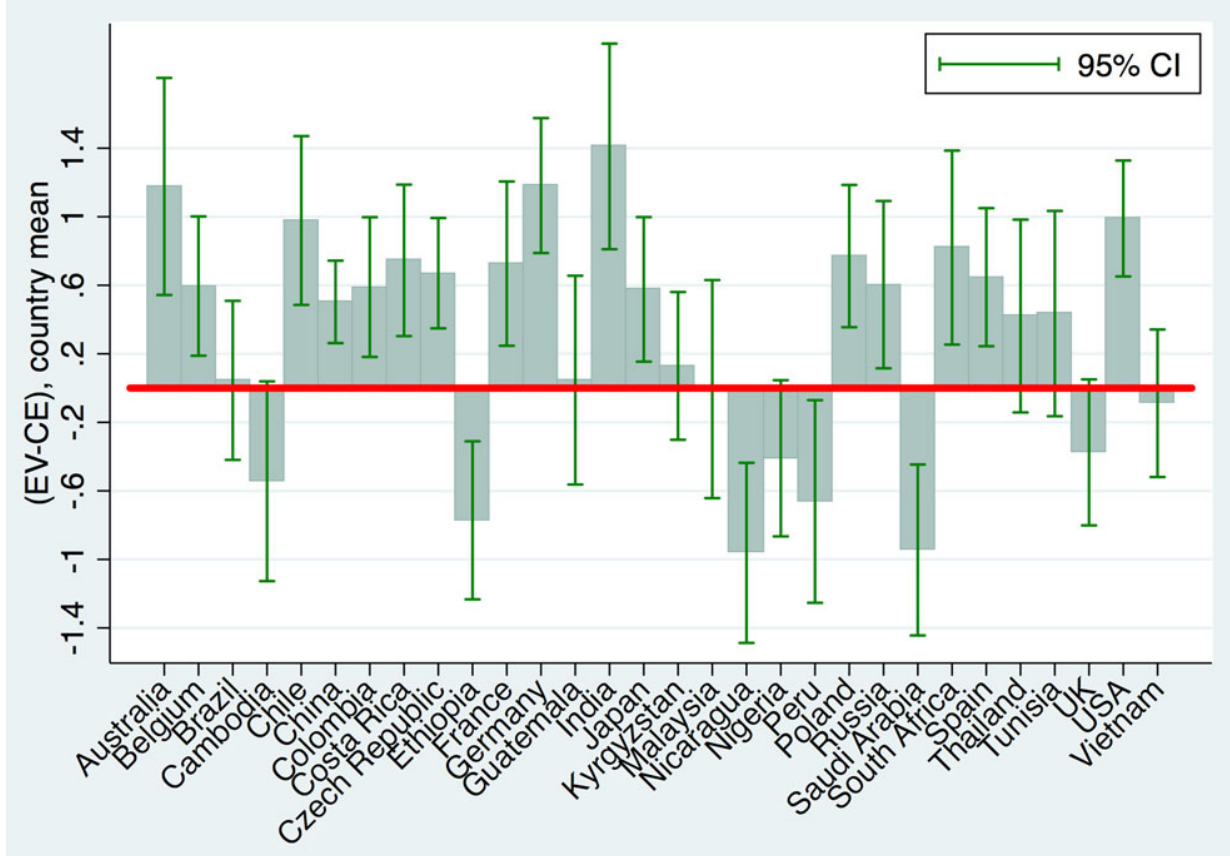

FIGURE 3. Average risk premia by country, risky gains.

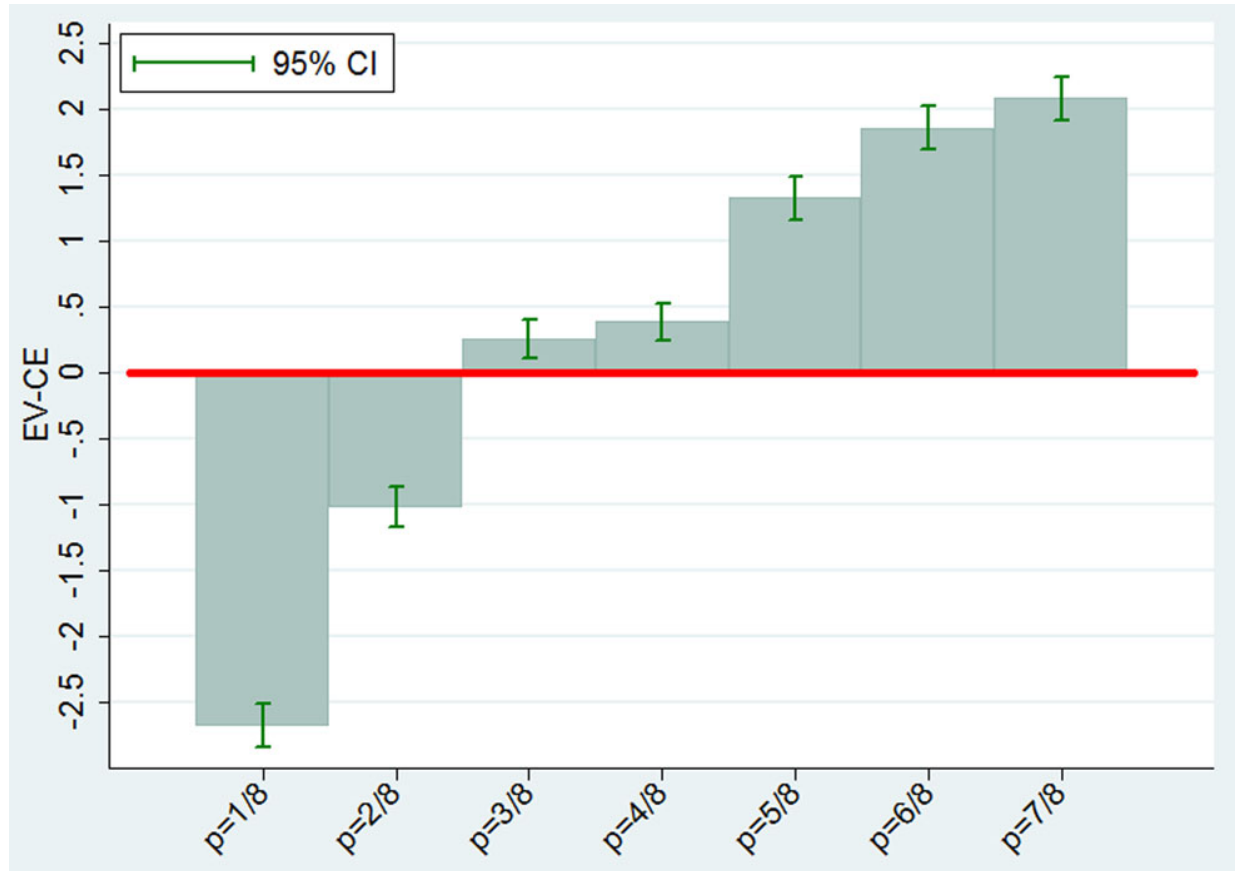

FIGURE 4. Risk premia by probability, risky gains. 
uncertainty and losses can be found in the Online Appendix). The trend indicates a pattern of risk seeking for small probabilities and risk aversion for moderate to large probabilities, which is the typical pattern found in the risk literature (Abdellaoui 2000; Fehr-Duda and Epper 2012; Kahneman and Tversky 1979; Wu and Gonzalez 1999).

This leaves us with the "stated preference" survey questions. We code the scale so that higher values indicate more risk aversion, just as for the incentivized measures. We also normalize the scales so as to make their midpoint correspond to 0 , so that they range from -5 to 5 . Figure 5 shows an overview of the answers to the general and financial survey questions country by country (equivalent graphs for other survey questions can be found in the Online Appendix). For the general survey question, depicted in Figure 5(a), the great majority of countries have a mean value below 0. It is somewhat unclear why this happens, but may be a product of a tendency towards selfreported optimism. It could also result from the "general" nature of risk preferences asked for, which would thus include small probabilities and losses, for which subjects tend to be more risk seeking. Be that as it may, unlike the EV for an incentivized prospect the midpoint of the scale constitutes no objective benchmark, and even the interpretation of the endpoint of the scale indicating that a subject is "fully prepared to take risks" is highly subjective.

Figure 5(b) displays the equivalent measures for the financial risk survey question. The picture is now reversed, with most means above 0 , indicating the midpoint of the survey scale. This suggests that people consider themselves to be more cautious in financial matters than in general. We again find considerable heterogeneity between countries. Before turning to the latter, we will now take a closer look at within-country correlations between the incentivized and survey-based risk measures.

\subsection{Within-Country Validation of Survey Measures}

This section addresses the issue of whether the correlation between survey measures and incentivized measures holds in different countries or whether it is culturedependent. We start, however, by examining the distributions of answers to the survey question compared to the distributions of the mean risk premium for all countries jointly, displayed in Figure 6. For reasons of parsimony, we limit ourselves to showing the graphs for the general survey measure, with the corresponding graphs for the financial survey question reported in the Online Appendix (country by country graphs are also shown in the Online Appendix).

The answer to the survey question is clearly skewed to the left, with its mode at -2 . A second anomaly that stands out is the peak at -5 , indicating that the respondent is "fully prepared to take risks". A look at country-by-country distributions indicates that this extreme peak is driven mostly by some countries that are indeed very risk seeking using incentivized measures, in particular Nicaragua and Nigeria, and to a lesser degree, Ethiopia, Vietnam, and Peru. The incentivized measures, however, typically exhibit a peak at or close to 0 , indicating risk neutrality. The distributions appear to be somewhat narrower for risk than for uncertainty. 


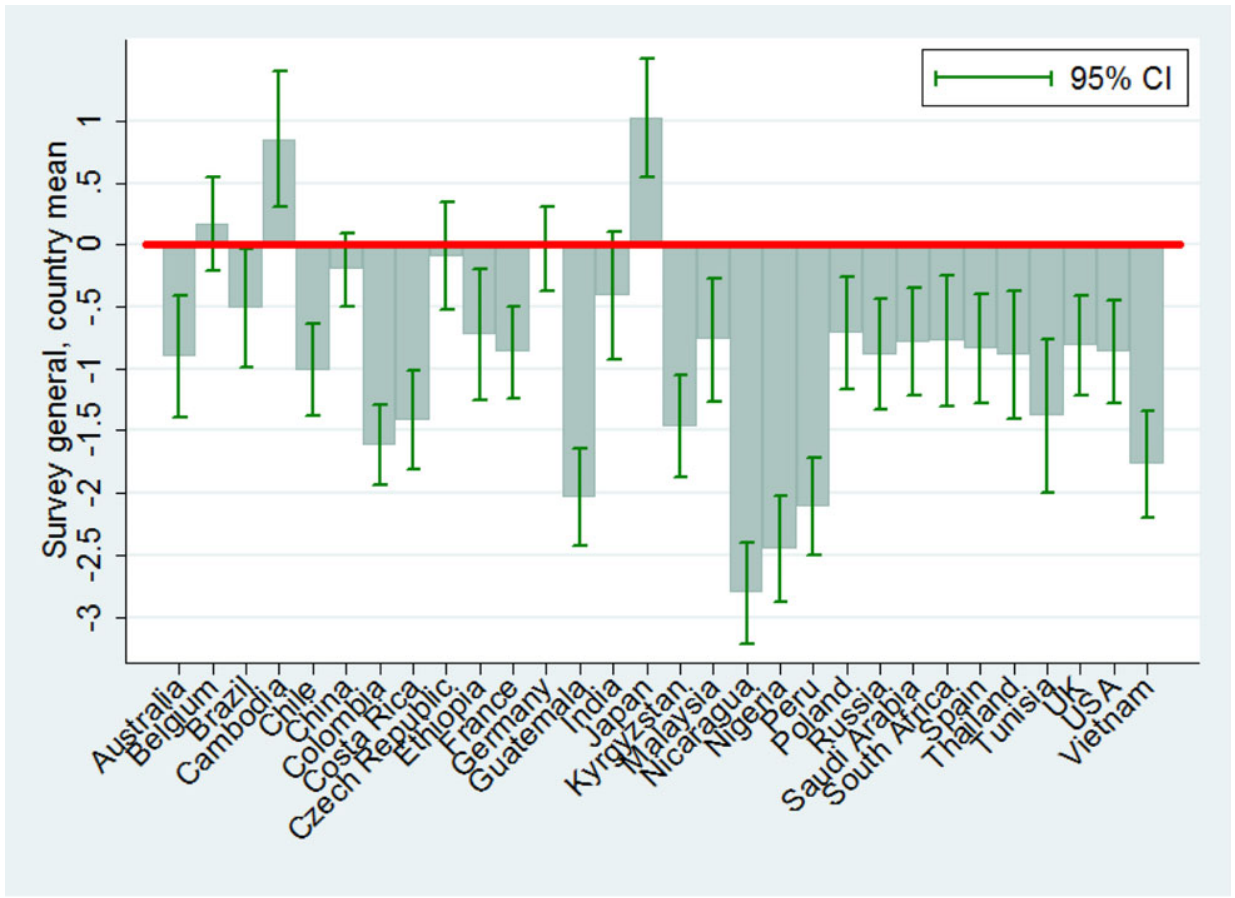

(a) General survey question

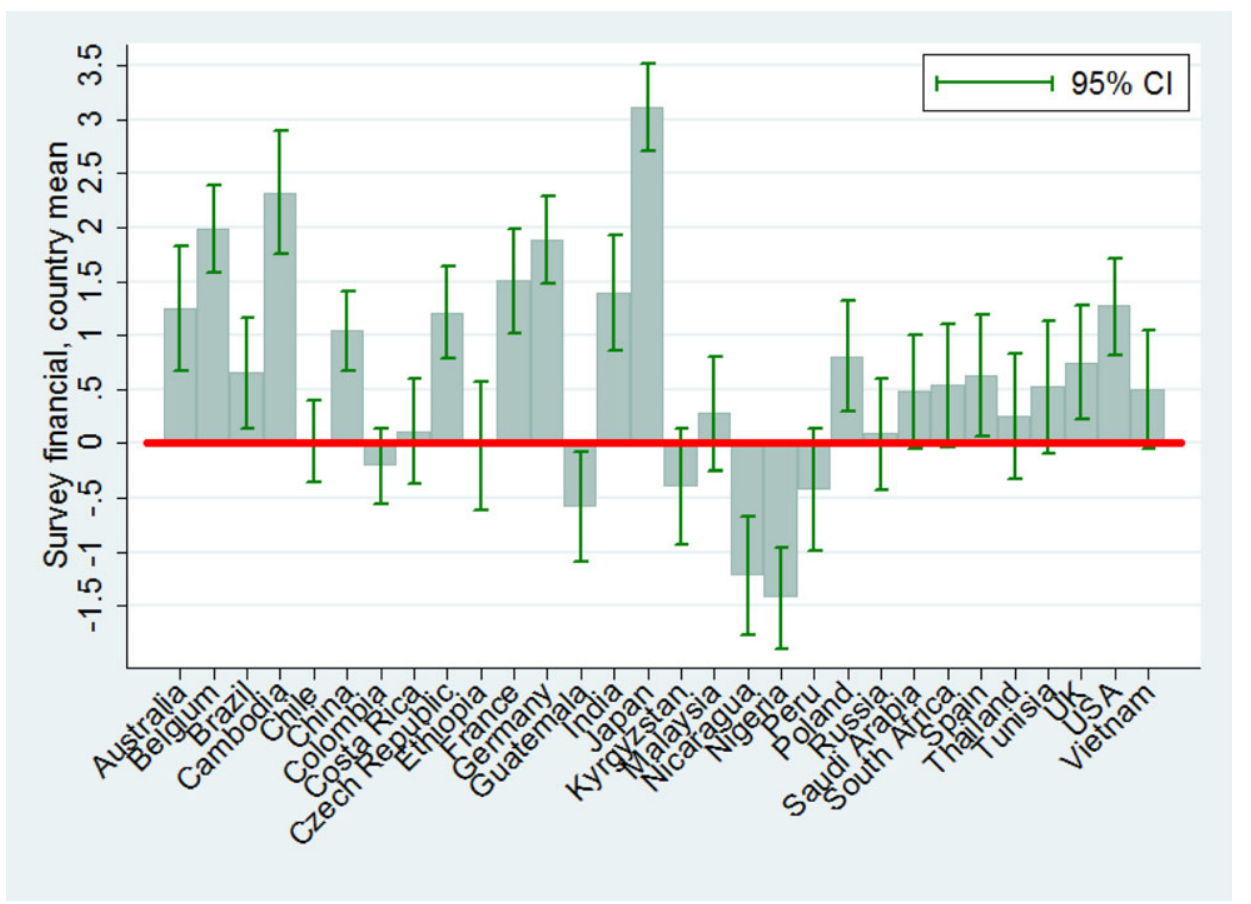

(b) Financial survey question

FIGURE 5. General and financial survey questions by country. 


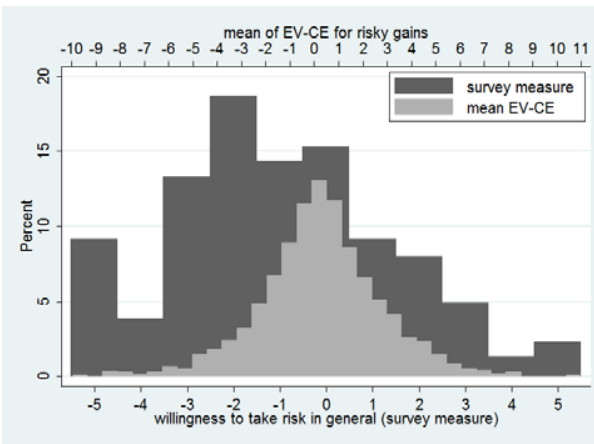

(a) Risk in the gain domain

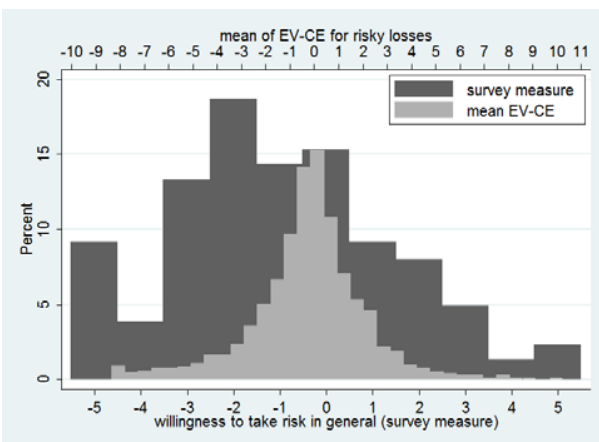

(c) Risk in the loss domain

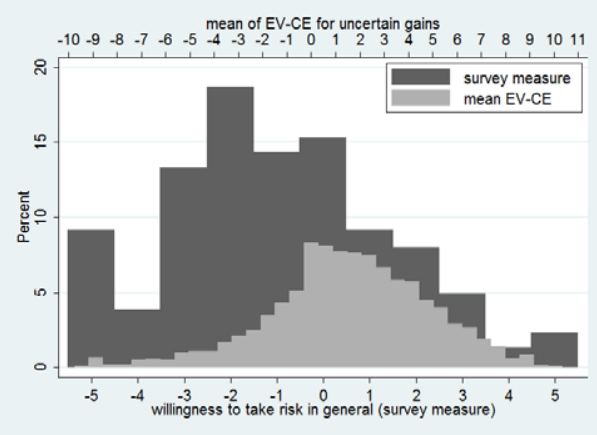

(b) Uncertainty in the gain domain

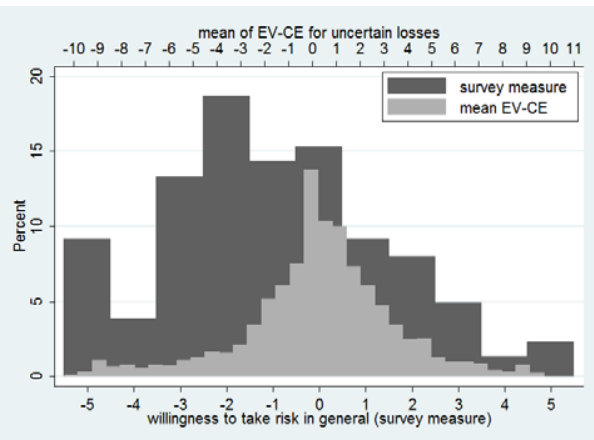

(d) Uncertainty in the loss domain

FIGURE 6. Global distribution of incentivized measures and general survey question.

Table 1 presents Spearman's $\rho$ together with its $p$-value for the correlations between each of our four incentivized measures with the general and the financial survey measure country by country (correlations with other survey measures, as well as correlations using different aggregate measures and for individual prospects, can be found in the Online Appendix). All $p$-values throughout the paper are two-sided unless indicated otherwise - a stringent test for our data since we have a clear unidirectional hypothesis.

In addition to the country-by-country correlations, the table contains some summary measures at the bottom, which will help us paint a picture of the general trends. The first one is a mean of the country-level correlations. We also add the number of correlations out of 30 in total going in the expected direction, the number of significantly positive correlations (conforming to our hypothesis) and the number of significantly negative correlations (contradicting our hypothesis). Finally, we test for each correlation count whether the number of correlations found is significantly superior to the one we would expect by chance using a binomial test (significant effects are emphasized in bold). For the simple count of positive correlations, we thus test the count against $50 \%$, the number we would expect to be positive by chance alone. In 


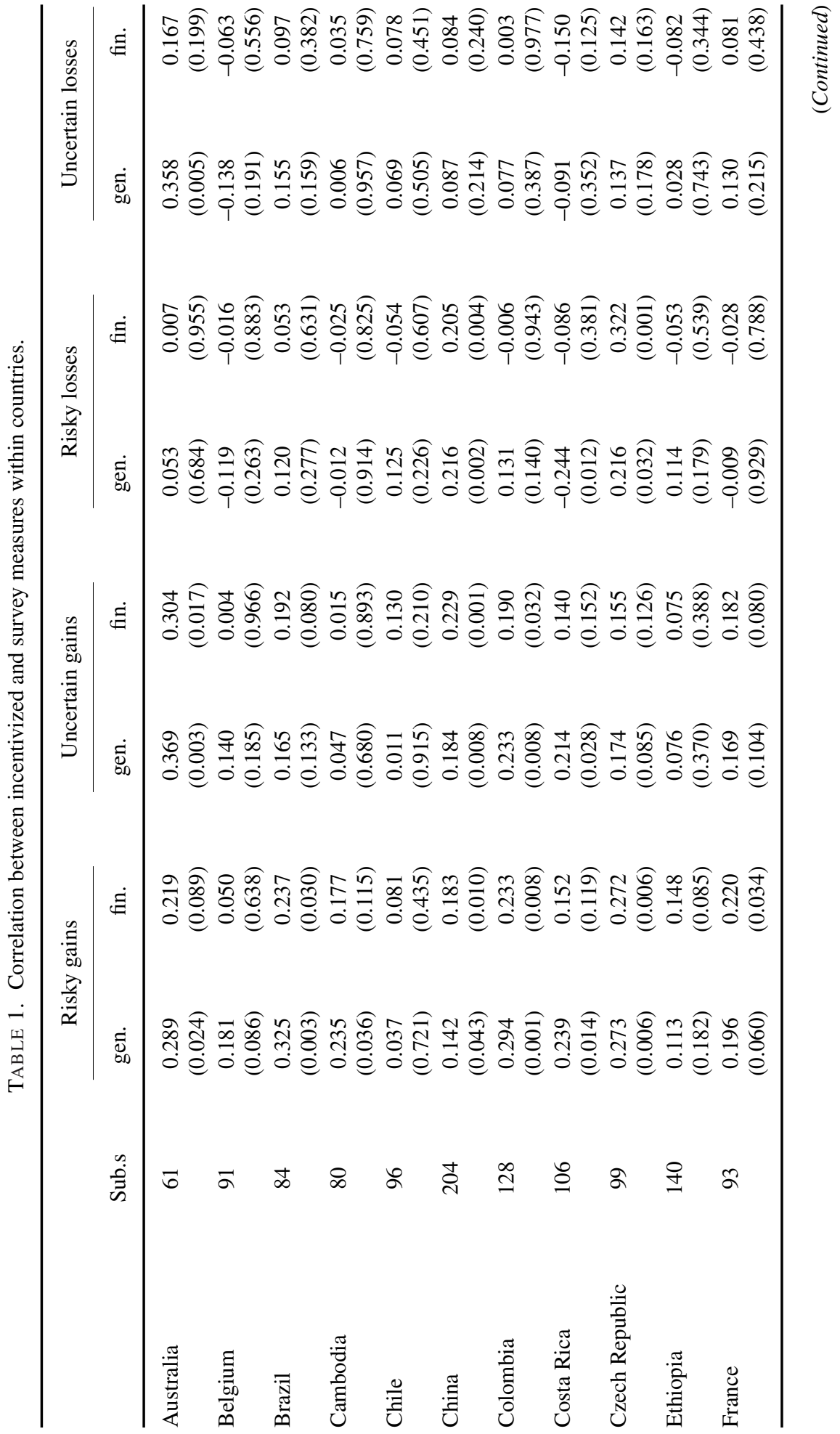




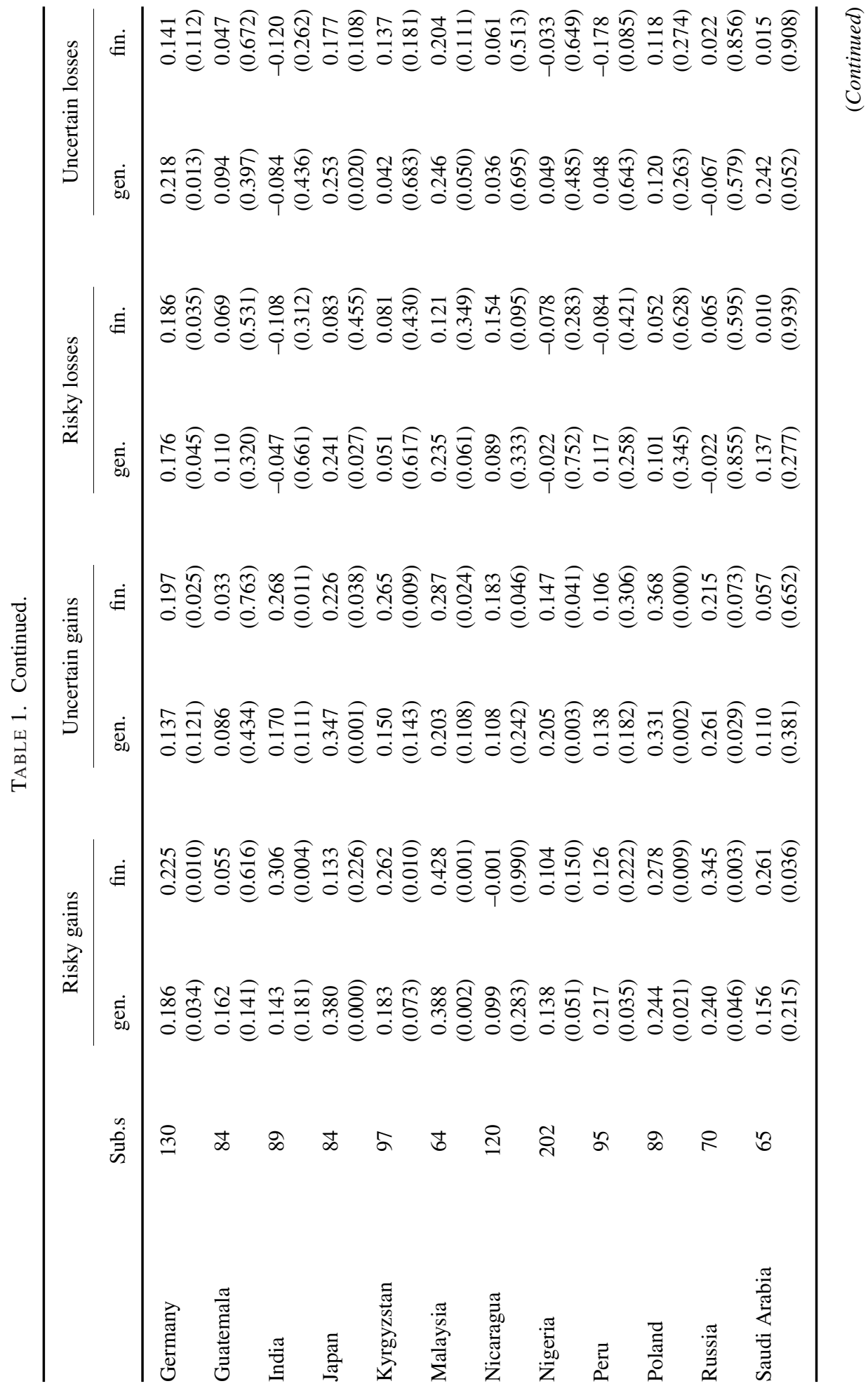




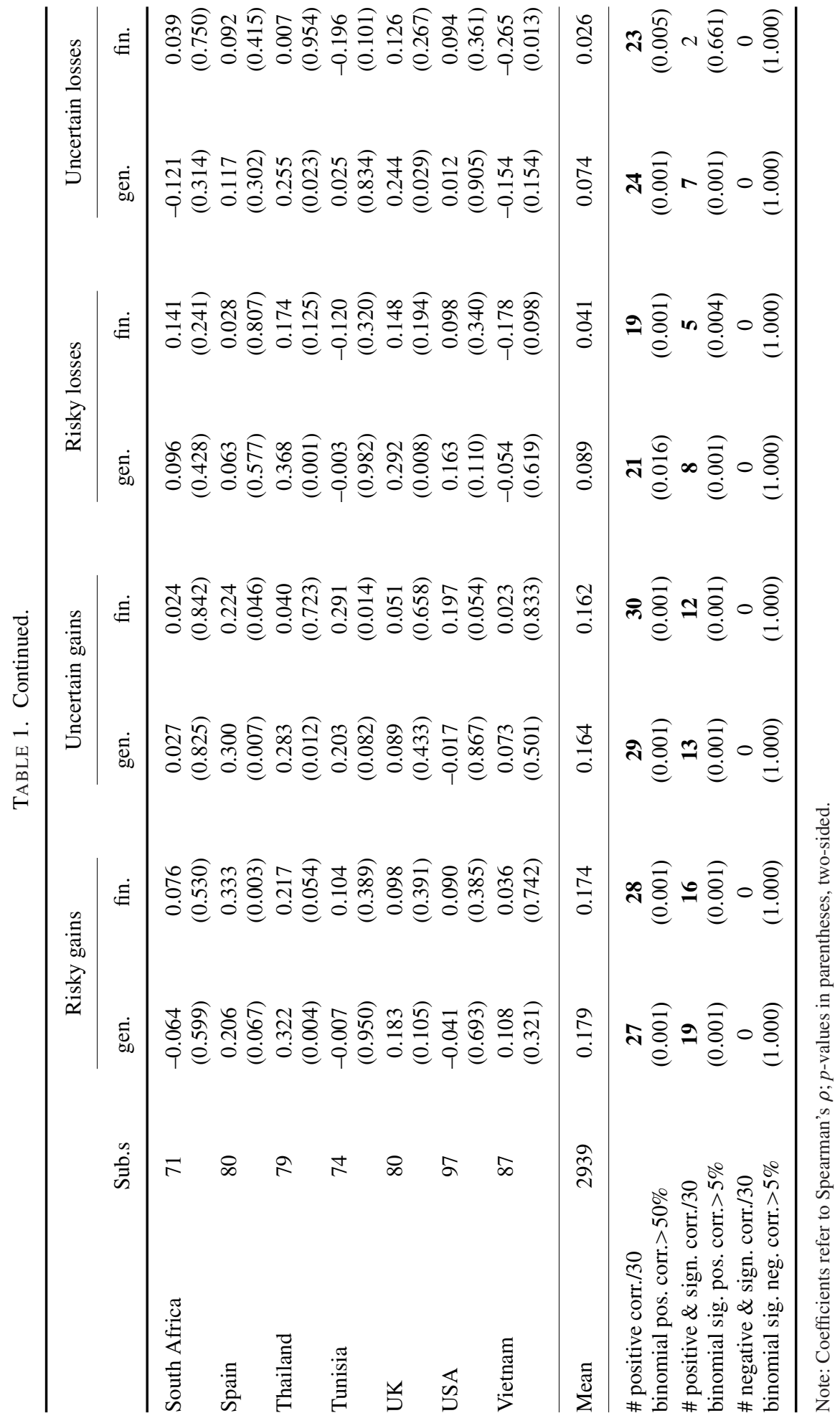




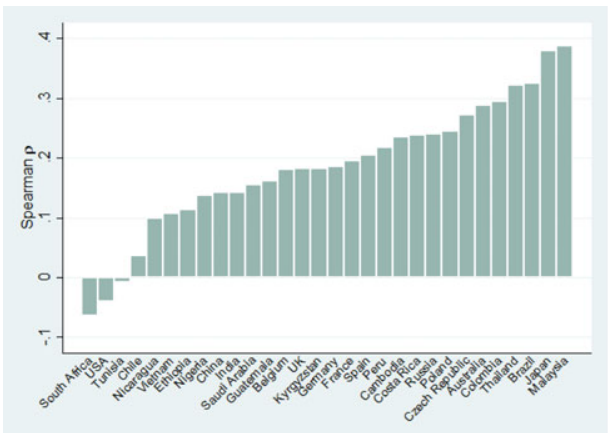

(a) Risky gains, general survey question

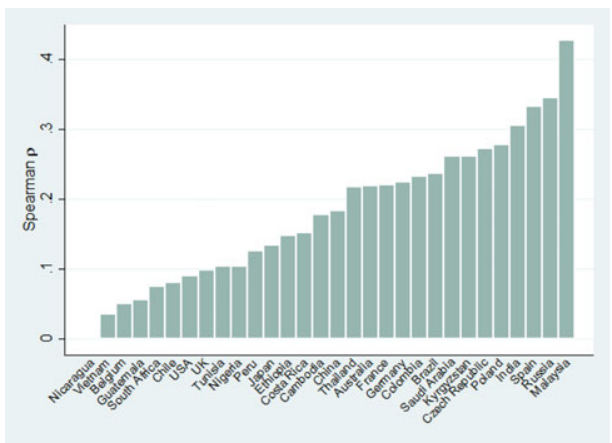

(c) Risky gains, financial survey question

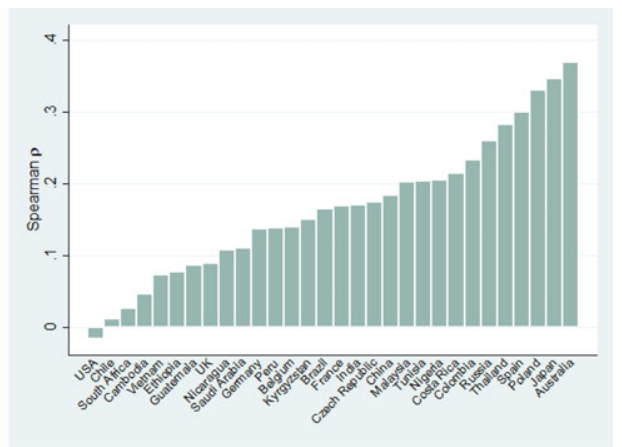

(b) Uncertain gains, general survey question

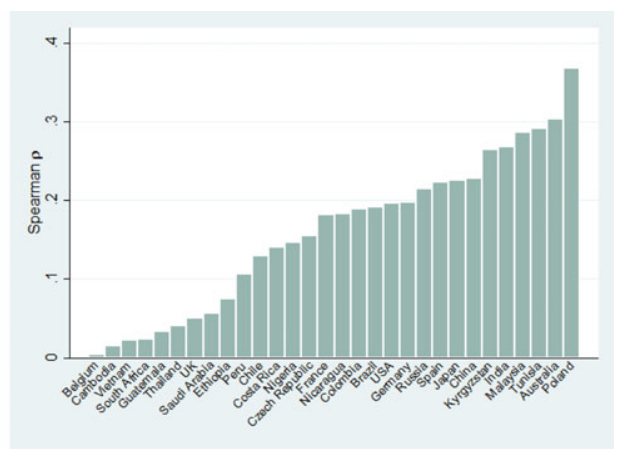

(d) Uncertain gains, financial survey question

FIGURE 7. Country-level correlation coefficients ordered by size, gains.

terms of the significant correlations, we would expect $10 \%$ (or three) of our countries to show significant correlations by chance (since we also count effects significant at the $10 \%$ level), $5 \%$ positive and $5 \%$ negative. To test whether the correlations we find are more than predicted simply by the chosen significance level, we thus compare the proportion of significant correlations in either direction to a $5 \%$ benchmark.

A clear picture emerges from the table. The positive correlations, indicating higher risk aversion as measured by the incentivized measures to be associated with higher stated risk aversion, are significantly more than expected by pure chance for all incentivized measures and both the general and the financial survey measure. The correlations appear best for risky and uncertain gains. We find particularly strong results for the incentivized measure for risky gains and the general survey question, with 19 out of 30 countries showing significantly positive correlations. This is followed closely by the correlation between risky gains and the financial question ( 28 positive, 16 significantly so), the correlation between uncertain gains and the general survey question (29 positive, 13 significantly so), and the one between uncertain gains and the financial question (30 positive, 12 significantly so).

The correlation coefficients for gains are displayed in Figure 7, with countries now ordered by coefficient size. The correlation coefficients vary widely, from about zero 
and even slightly negative (but nonsignificantly so) to about 0.4 in all four cases. The median coefficients hover around 0.2 for risky gains and the general survey question, and only slightly below that for the other correlations. It is hard to spot clear trends for individual countries. The United States, for instance, performs rather poorly in three out of the four correlations, but is clearly above the mean for the correlation between uncertain gains and the financial survey question. Saudi Arabia has mostly correlation coefficients falling in the lower half of the spectrum, but only one of them is very low, and the lacking significance reflects at least in part relatively low subject numbers. The correlations are generally weaker for losses, even though there are still significantly more positive correlations than would have been expected by pure chance in all cases but the relation between uncertain losses and the financial survey question. Figures of correlation coefficients for losses can be found in the Online Appendix.

We may want to ask ourselves why we would expect a positive correlation with loss measures at all. Certainly, one of the survey questions asks for risk attitudes "in general", thus suggesting such an approach. One could, however, easily make the opposite case based on the four-fold pattern of risk attitudes that has been found in much of the empirical literature (Abdellaoui 2000; Fehr-Duda and Epper 2012), and which we also find in our data. According to this so-called reflection effect, risk aversion for moderate-to-large probability gains goes hand in hand with risk seeking for losses of the same probability; for small probabilities, however, risk seeking for gains will be mirrored by risk aversion for losses. While this pattern generally holds in the aggregate, little evidence supporting it has been found at the individual level (Cohen, Jaffray, and Said 1987; Schoemaker 1990). This raises the issue to what extent and in what direction decisions under uncertainty are generally correlated between gains and losses - a question that will be addressed in what follows.

\subsection{Between-Country Correlation Results}

The fact that we find positive correlations as expected within most countries at the individual level does not guarantee that the same result will obtain between countries. Cultural factors may affect the absolute responses on the survey questions even while relative responses within a given country reflect within-country differences in revealed risk preferences. This is much less likely to occur in the incentivized questions, where money and probabilities constitute objective parameters that are invariant across countries. Since we are now purely considering country-level results, we take the average at the country level for the different measures. For the survey questions, this is the simple average of the measure, separately for each decision context. For the incentivized measures, we take the average of the mean by domain and uncertainty source - that is, the country average of the individual means for risky gains, uncertain gains, risky losses, and uncertain losses. Results for alternative aggregate measures such as country-level medians are reported in the Online Appendix.

Table 2 reports the between-country correlations of the four incentivized measures with the general and the financial survey questions. Correlations with other survey questions seem less relevant (and less likely to work), and are reported in the Online 
TABLE 2. Correlations at the country level.

\begin{tabular}{lcccc}
\hline$N=30$ & Risky gains & Uncertain gains & Risky losses & Uncertain losses \\
\hline Survey general & 0.261 & 0.316 & 0.325 & 0.374 \\
& $(0.164)$ & $(0.089)$ & $(0.080)$ & $(0.042)$ \\
Survey financial & 0.479 & 0.451 & 0.382 & 0.384 \\
& $(0.007)$ & $(0.012)$ & $(0.037)$ & $(0.036)$ \\
\hline
\end{tabular}

Note: Coefficients refer to Spearman's $\rho$; $p$-values in parentheses, two-sided.

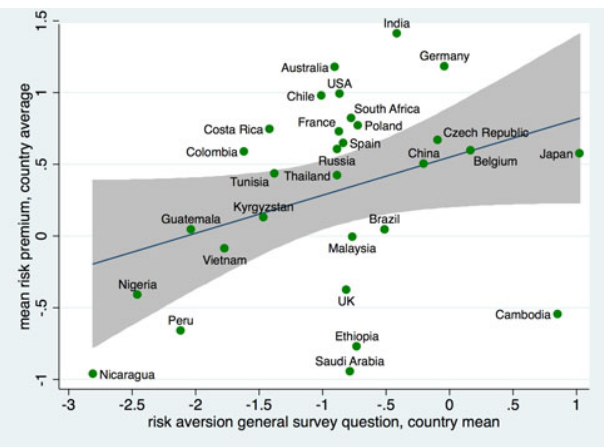

(a) Risky gains and general survey

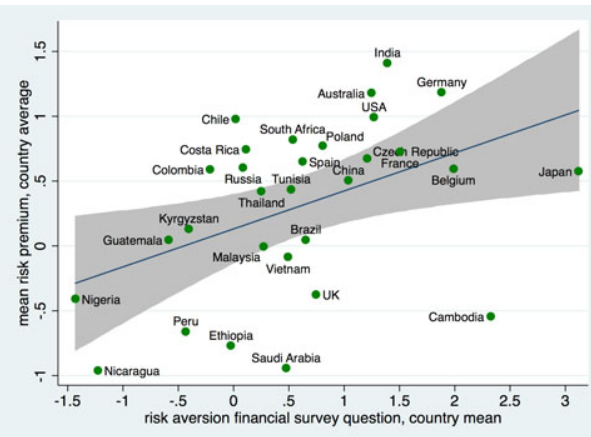

(c) Risky gains and financial survey

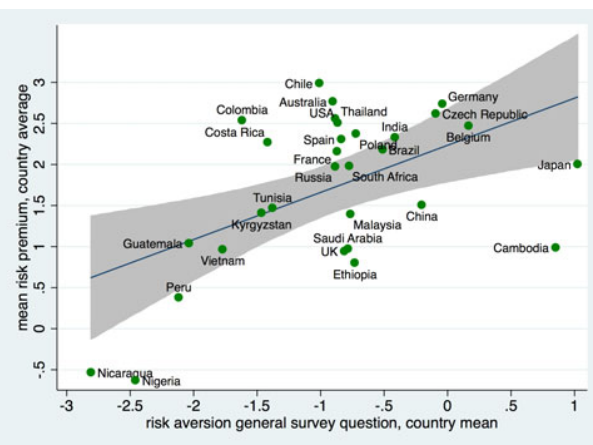

(b) Uncertain gains and general survey

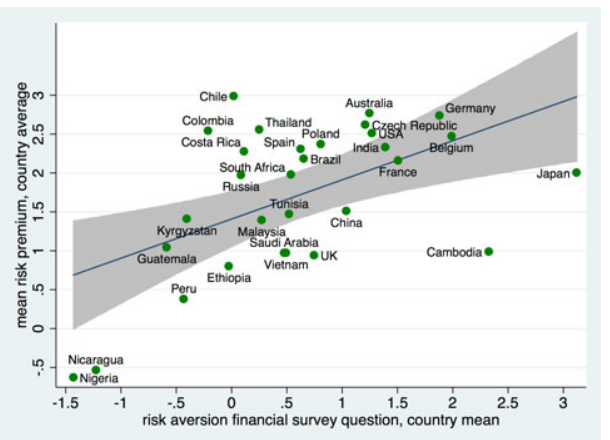

(d) Uncertain gains and financial survey

FIGURE 8. Country-level correlations for gains.

Appendix. All correlations are positive, indicating that more revealed risk aversion at the country level corresponds generally to higher stated risk aversion. This effect is significant for all correlations except the one between the incentivized measure for risky gains and the general survey question ( $p=0.16$, two-sided). The correlation coefficients are generally larger than or close to the largest ones observed across the different countries at the individual level. As to the significance, one ought to also keep in mind the relatively small sample size of $N=30$.

The correlations between the two survey questions and the incentivized summary measures for gains are displayed in Figure 8, with Figure 8(a) showing the correlation 


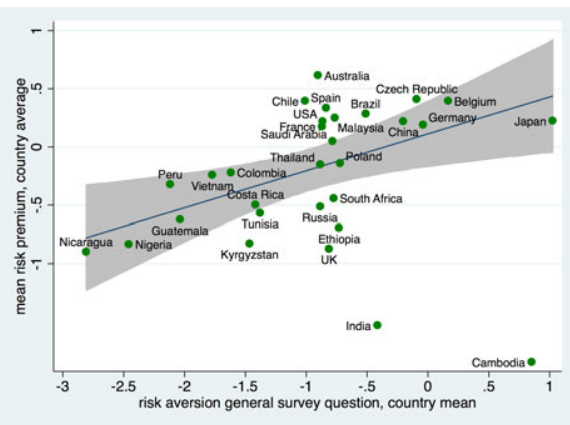

(a) Risky losses and general survey

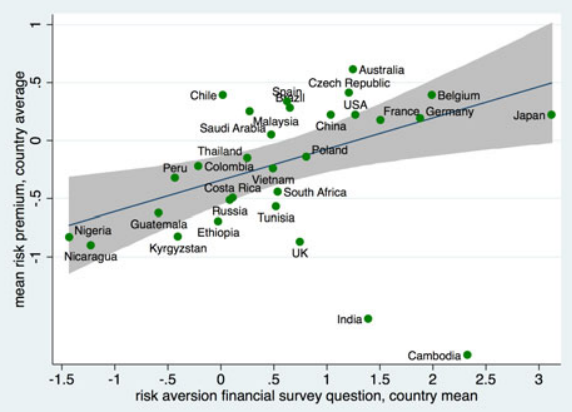

(c) Risky losses and financial survey

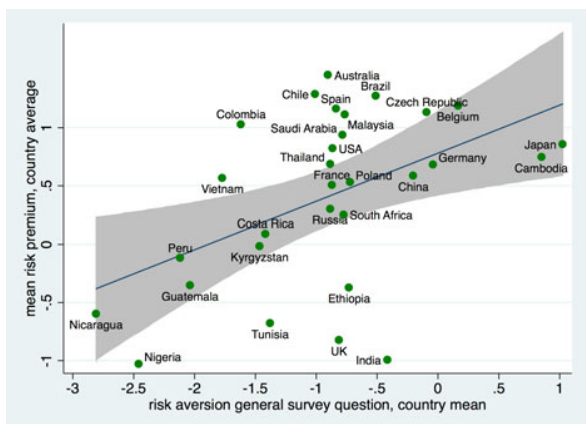

(b) Uncertain losses and general survey

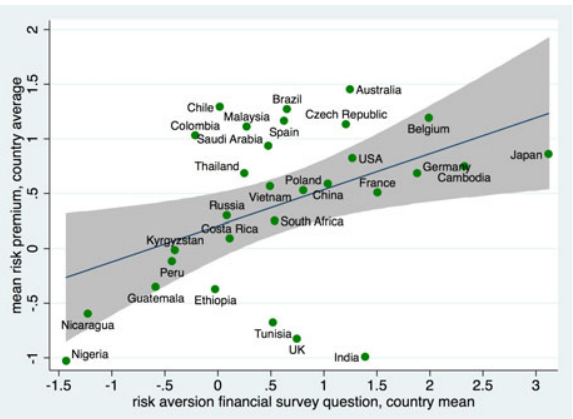

(d) Uncertain losses and financial survey

FIGURE 9. Country-level correlations for losses.

between risk and the general survey measure, $8(\mathrm{~b})$ the correlation between uncertainty and the general survey measure, 8(c) the correlation between risk and the financial survey measure, and $8(\mathrm{~d})$ the correlation between uncertainty and the financial survey measure. All show a clear trend, and there appear to be fewer outliers for uncertainty than for risk. This provides an indication that both the financial and the general survey question may capture a concept that is closer to uncertainty attitudes than to risk attitudes.

For losses the correlations are again positive as expected. All of them are significant, and the correlation coefficients are once again large compared to typical individuallevel coefficients discussed previously, as well as compared to typical correlation coefficients at the individual level reported in the previous literature (e.g., Dohmen et al. 2011b). This holds especially for uncertainty, for which there again appear to be fewer outliers. The effects are depicted in Figure 9.

\subsection{Context-Specificity versus Common Components in Risk Attitudes}

We have so far only considered the answer to the general and financial survey questions. Furthermore, we have focused on the correlations between revealed and 
stated preferences. This, however, sidesteps another important issue-the extent to which different measures of risk preferences correlate with each other in general, for instance between gains and losses, or between different sources of uncertainty and across contexts. We will now address this question by examining pairwise correlations between all the different measures, across uncertainty sources, decision domains, and all contexts.

Table 3 shows the correlation matrix for all subjects across the different countries (analogous tables country by country can be found in the Online Appendix). The correlations can be seen to vary widely, from a correlation of 0.68 between gains under risk and under uncertainty, to close to zero and nonsignificant (e.g. risky losses and driving). A few clear trends do, however, emerge. For instance, the mean risk premium for risky gains correlates significantly with all other measures but the health survey question, be they incentivized or survey-based, and under both gains and losses. The correlation is strongest with the incentivized measure for uncertain gains, followed by the survey questions on willingness to take risk in general and financial risks. The correlation is weakest with willingness to take risks in health (which is also not significant), in sports, and with other people. Similar findings hold for uncertain gains. There is also a highly significant correlation with decisions for losses. The latter goes in the direction that people who are more risk averse in the gain domain are generally also more risk averse in the loss domain. This holds for both risk and uncertainty in both decision domains, and is generally stronger for uncertainty than for risk.

A measure that correlates with all other measures is the survey question on willingness to take risks in general (and similarly the financial survey question). The correlations are relatively strong with most of the other survey measures, as well as with the incentivized measures over gains. The correlations with the incentivized measures over losses perform less well. This finding runs counter to the argument that responses to the survey measures may have been influenced by previous choices in the incentivized tasks. Since losses were always presented after gains, we would expect responses to the survey question to be influenced rather by the responses to the loss questions than the gain questions if this were the case. As we can see it is not. By and large, we can conclude that most measures show a highly significant correlation with most other measures, pointing in the direction that there exists some underlying general risk preference that shows itself in all the different measures. The strength of the correlations is similar to the ones observed in Germany by Dohmen et al. (2011b). The correlations between measures in the gain and in the loss domain are somewhat stronger than the correlations found between investment and insurance decisions reported by Einav et al. (2012).

We now proceed to regression analysis to determine the extent to which the different measures of uncertainty attitudes share the same correlates. We use OLS regressions throughout. The results are presented in Table 4 . Self-declared foreigners in any given country were dropped from the analysis, but our results are stable to including them (see the Online Appendix). The explained variance is very low in some regressions, especially so in the survey questions on contexts other than the general and financial one. Each regression includes a number of predictors, which fall into three categories: biological predictors, specifically sex and age; the study major of the subject, measured 


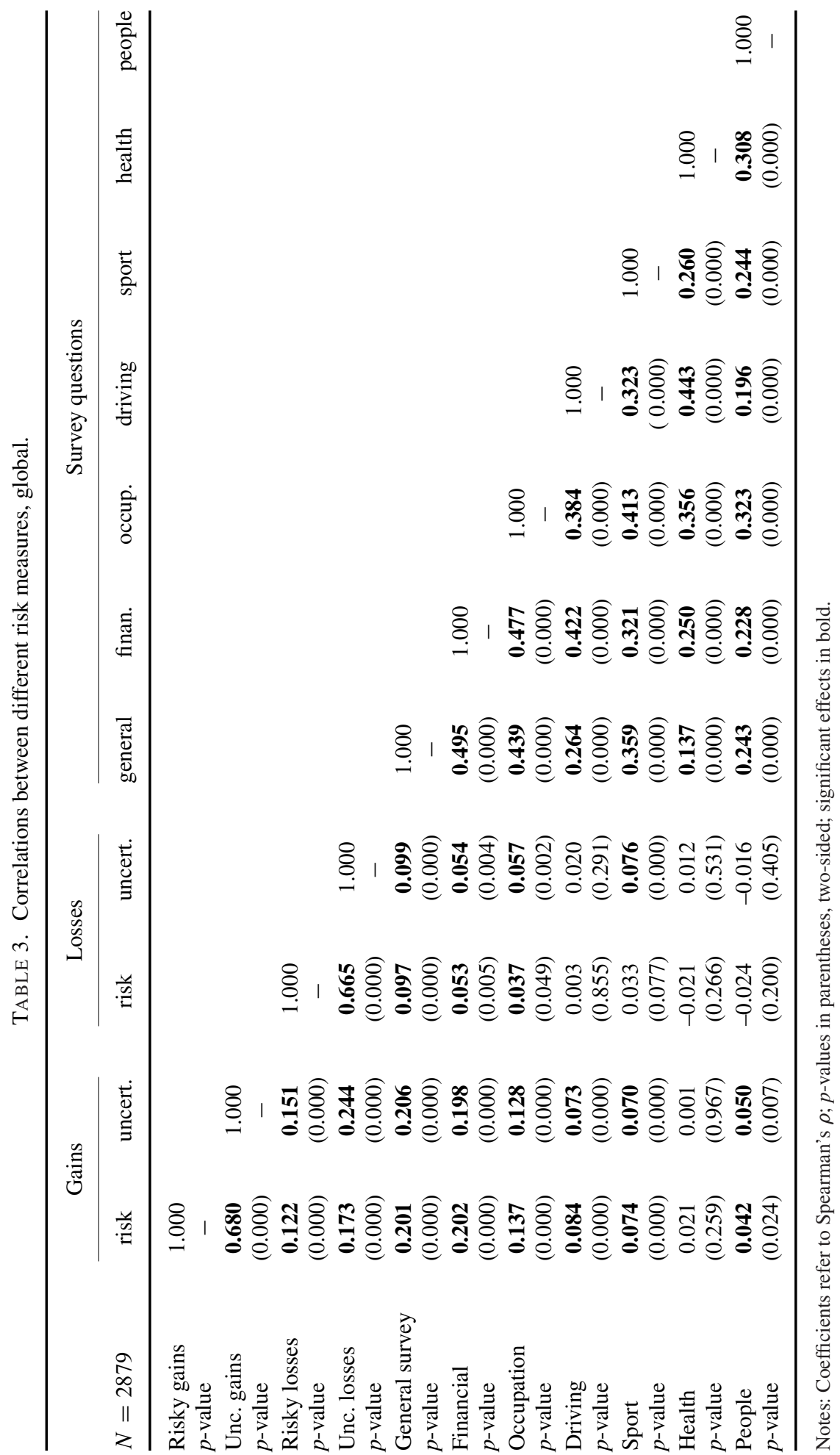


苛

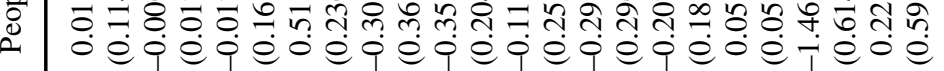
$\stackrel{n}{\stackrel{n}{*}} \underset{0}{0}$

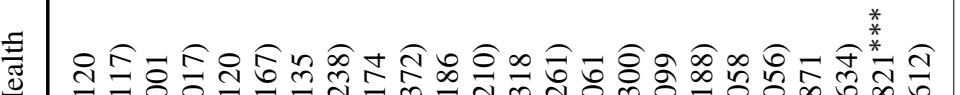

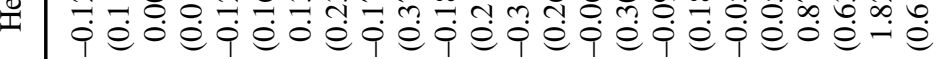
$\stackrel{2}{\stackrel{2}{1}}$

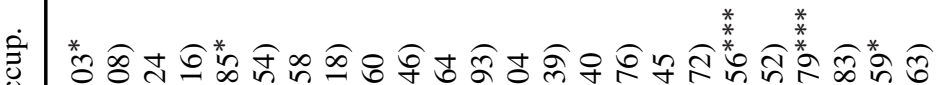
o ปे
$\stackrel{2}{0}$

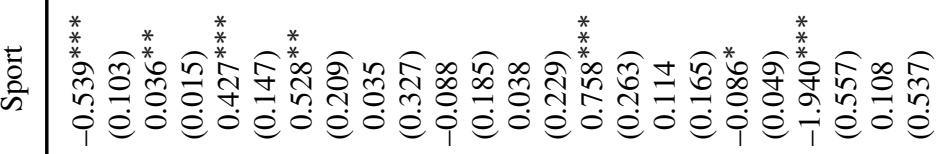
$\stackrel{\text { ก }}{\stackrel{1}{0}}$ so $\stackrel{*}{*}$

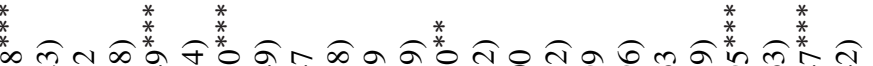

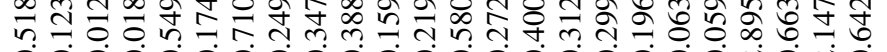

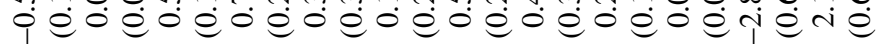

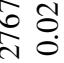
*

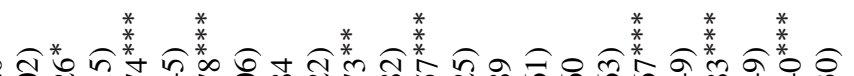

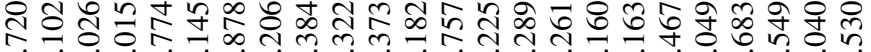

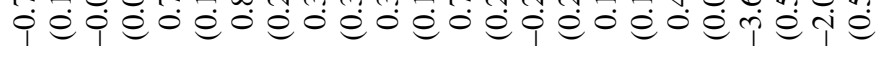

웅

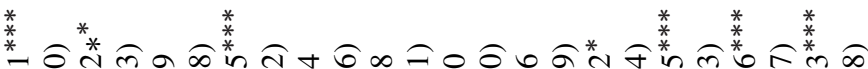

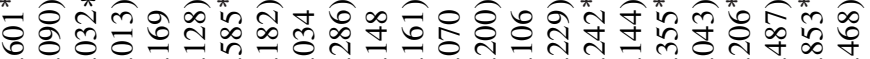

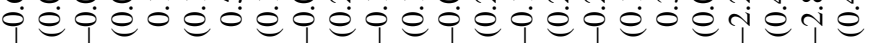

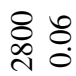

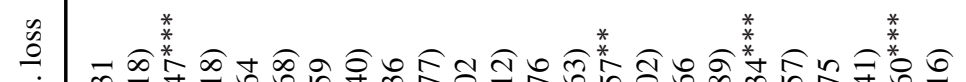
๖

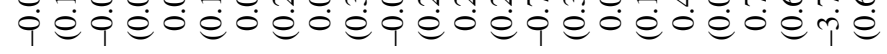
$\underset{\substack{\infty \\ \infty}}{\substack{0 \\ 0}}$

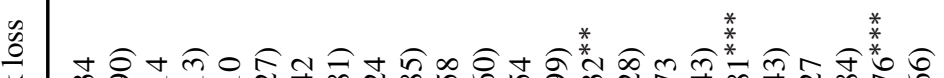

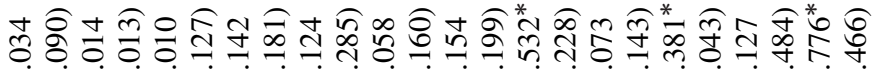
$\stackrel{\substack{0 \\ 0}}{0}$

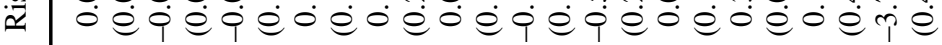

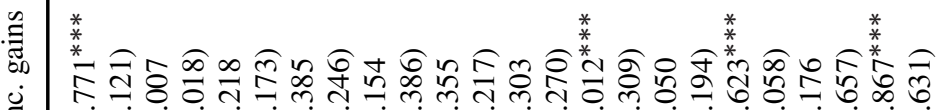

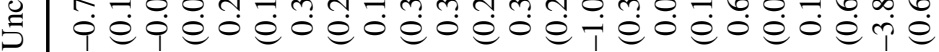

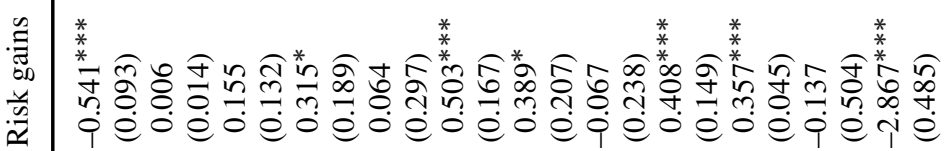

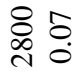

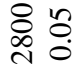

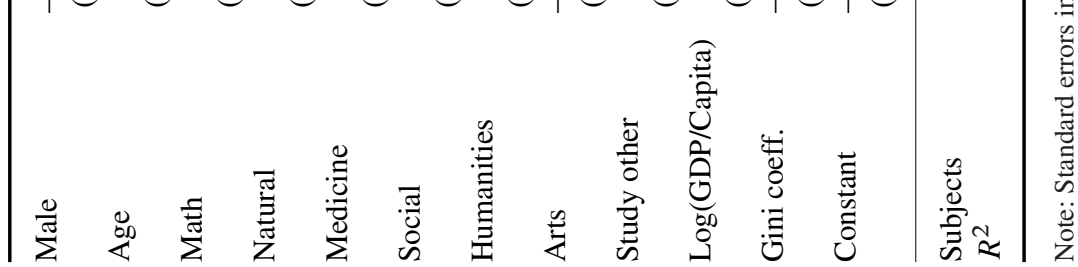


relative to economics students; and macroeconomic factors, such as GDP per capita, and the Gini coefficient. ${ }^{3}$ The Online Appendix contains additional regressions in which we add the individual, group, and country characteristics one after the other; it also contains a regression where we add country fixed effects instead of GDP. All effects described hereafter are stable to these alternative specifications.

Although some doubts on the stability of the relation remain, women have often been found to be more risk averse than men (Croson and Gneezy 2009). We confirm this effect for our incentivized measures for gains but not for losses, where we find no significant effect. In terms of the survey measure, we again find a gender effect for most contexts. The exceptions to this rule are the health context and the people or social context, where the gender effect is not significant. We find only weak (and inconsistent) effects in terms of age, although this is not surprising given the narrow age range of our subjects. Moving on to study majors, we find an interesting tendency amongst mathematics and natural science majors, who generally declare themselves to be less risk taking than the comparison group of economics students in the survey questions, while in incentivized measures they take just as much risk. In addition, students of the humanities and of the social sciences other than economics tend to be more risk averse, although this effect is only significant for some of the measures. Art students take more risk than economics majors for the incentivized gain measures, but declare themselves to be considerably more risk averse in the sports context.

The strongest and most consistent effects are observed for the (log of) GDP per capita measure (for 2011 in PPP terms; source: World Bank). Subjects from countries with lower GDP per capita are more willing to accept uncertainty for the incentivized measure across all domains and uncertainty sources. The effect is economically strong as well as highly significant (see discussion). The same effect is also found for the general survey question, occupational risks, and financial risks. For sports it goes in the opposite direction, with people from richer countries declaring themselves more willing to take risks. The effect is not significant for driving risks, health risks, and social risks. We will return to these effects in the discussion. In addition, we find strong effects of the Gini coefficient - a proxy for income inequality in a country — on stated risk taking, but not on revealed risk taking. For a discussion of the relation between income inequality and risk preferences, see for instance Friedman (1953) and Kanbur (1979).

\section{Discussion and Conclusions}

We can clearly conclude that, by and large, survey instruments aimed at measuring risk attitudes correlate with decisions in which real money is at stake. This does not only work within most of our 30 countries, but also at the macroeconomic level across countries - an encouraging finding that may pave the way for the use of survey

3. Some of the individual factors and groups are absent in some countries-for example, no women have taken part in the experiment in Saudi Arabia. All findings in the regression remain stable if we eliminate such countries. 
measures in cross country comparisons of general population samples. The finding that the correlations work between countries as well as within suggests that subjects are aware of their position within the scale, which is naturally constrained between the two endpoints for the survey questions. This in turn suggests that also the mean values on the survey scales between contexts have some meaning. For instance, we find much less stated risk aversion on the survey question asking for risk preferences in general than on the one asking for financial risk taking or risk taking in health aspects. The differences in absolute values on the various scales may thus constitute an opportunity rather than a problem. All the more so since we know that even incentivized scales do not produce absolute rankings that are impervious to changes in elicitation, given that they have been found to be highly sensitive to the monetary stakes used (e.g. Binswanger 1980; Kachelmeier and Shehata, 1992; Lefebvre, Vieider, and Villeval 2010).

Another interesting insight derives from the correlation analysis of the various measures. Psychologists have generally concluded that risk attitudes are contextspecific, and that there exists little or no relation of risk attitudes in one context to risk attitudes in another (Weber, Blais, and Betz 2002). Economists, however, have tended to emphasize the underlying component common to choices across different contexts and domains (Dohmen et al. 2011b; Einav et al. 2012). Our results tend to support the latter view, as we found uncertainty attitudes to be clearly related across most contexts and domains. Perhaps, however, it is wrong to think about the issue in a bipolar fashion, since it rather appears to be a matter of degree. Given our results, many scholars might still counter that the correlations found are rather weak, and preferences thus highly context-dependent. However, the correlations are highly significant and appear to be stable; and most measures present the same correlates in regressions, further indicating a common underlying component constituting uncertainty attitudes.

The existence of some underlying element of uncertainty attitudes also allows us to address a more philosophical question about the existence of stable preferences. Slovic (1995) proposed three possible views on the nature of values and preferences in general: (i) they exist a priori and are perfectly reported when elicited; (ii) they do exist a priori, but will be reported only imperfectly when elicited, depending on the method used and possibly the context to which they are applied (discovered preference hypothesis); and (iii) they are constructed during elicitation and will thus completely depend upon the particular circumstances of the elicitation method (constructed preference hypothesis). He indicated the last one to be most likely. Cubitt, Starmer, and Sugden (2001) and van de Kuilen (2007) lean towards the discovered preference hypothesis in applications of decision making under risk (see also Plott 1996). The common component to uncertainty attitudes elicited with different methodologies, across different domains, and in different contexts, clearly points to the conclusion that there does exist some fundamental "uncertainty attitude". We thus conclude that preferences are indeed discovered and derived from an underlying preference, rather than constructed ex nihilo.

All that said, our results are generally much weaker using survey measures in contexts other than the general or financial one. This holds both for the correlations between different measures, and for the association with regressors such as GDP. One could speculate about reasons why this happens. For instance, as far as the relation 
between GDP and risk aversion in sports is concerned, we find a marginally significant effect in the opposite direction of the relations observed for most other measures, with higher stated risk taking in richer countries. Plausibly, sport may be considered a luxury good, especially the types of thrill-seeking activity with high risk popular in the developed world (climbing, kite-surfing, paragliding, skiing, etc.). Poverty usually prevents such activities, a reason for which the typical Ethiopian is much more likely to simply go running (a comparatively low-risk activity). Also, our student subjects are unlikely to own a car, especially in poorer countries. This may explain the absence of an effect for driving (which may appear puzzling indeed if one compares traffic in Kolkata to traffic in Berlin, for instance).

While the finding that the (nonincentivized) survey measure correlates with (incentivized) measures of risk preferences is an interesting one, there are arguably limitations of using such survey measures in empirical work. For example, the survey measure does not permit the researcher to draw any conclusion about ambiguity aversion, loss aversion, or subjective probability distortions. All of these concepts are of relevance for understanding a broad number of economic phenomena (see e.g. Dimmock, Kouwenberg, and Wakker 2014, on ambiguity attitudes and portfolio choice, von Gaudecker, van Soest, and Wengstrom 2011, on the importance of loss aversion, and Barseghyan et al. 2013, on the importance of probability weighting for the choice of insurance deductibles). Scholars interested in studying the effects of finer characteristics of risk preferences therefore have no other choice than setting up incentivized lottery choice experiments (at least as long as there are no appropriate survey measures on the specific characteristics available).

Almost all our measures of risk preferences reveal a strong relationship between risk tolerance and per capita GDP. This is consistent with recent findings by Rieger, Wang, and Hens (2014), who obtained hypothetical measures of willingness to pay for lotteries in a survey conducted with economics students in 54 countries. This relationship indicates a risk-income paradox. Indeed, there exists ample (although not entirely consistent) evidence that risk aversion decreases in income within countries (e.g., Dohmen et al. 2011b; Donkers, Melenberg, and Van Soest 2001; Hopland, Matsen, and Strom 2013). We, however, find a strong positive correlation of national income with risk aversion. This paradox is more thoroughly described by Vieider et al. (2013) using data obtained with Vietnamese farmers, thus excluding explanations based on selection into university. Vieider, Chmura, and Martinsson (2012) provide empirical support for a possible explanation of the paradox based on unified growth theory, following a theoretical model developed by Galor and Michalopoulos (2012). According to that model, income per capita has been stable over the medium and long term for most of the time since humans started becoming sedentary about 13,000 years ago. In this "Malthusian" growth phase, the number of surviving offspring was strictly linked to income. Given transmission of risk preferences from parents to children, and given the within-country positive correlation between risk tolerance and income, risk tolerance would thus have spread as a general population trait. Starting with the industrial revolution, income per capita finally started to take off. More affluent segments of the population started a Beckerian transition, substituting quality for 
quantity of children. Poor population segments, however, were no longer limited by low incomes and started increasing their number of children. As a result, the risk aversion typical of poorer population segments started spreading.

In our analysis, we have paid considerable attention to different dimensions along which preferences are known to differ-the decision context, outcome framing by decision domain (gains versus losses), and the source of uncertainty. One dimension we have have largely neglected, however, is the one of likelihood-dependence. Our descriptive data shown at the beginning of the results section clearly show that this dimension is relevant, with risk preferences varying systematically across probabilities. The reason for this neglect is that such likelihood-dependence is best explained within a structural model that allows for nonlinear transformations of probabilities (Fehr-Duda and Epper 2012; Wakker 1994). Such a structural analysis of the current data using prospect theory is provided in L'Haridon et al. (2013).

\section{Appendix A: List of Prospects}

TABLE A.1. Decision tasks, amounts in euros.

\begin{tabular}{|c|c|c|c|}
\hline \multicolumn{2}{|c|}{ Gains } & \multicolumn{2}{|c|}{ Losses } \\
\hline Risk & Uncert. & Risk & Uncert. \\
\hline$(5,1 / 2 ; 0)$ & & $(-5,1 / 2 ; 0)$ & \\
\hline$\left(10, \frac{1}{2} ; 0\right)$ & & $(-10,1 / 2 ; 0)$ & \\
\hline$(20,1 / 2 ; 0)$ & & $(-20,1 / 2 ; 0)$ & \\
\hline$\left(30, \frac{1}{2} ; 0\right)$ & & $(-20,1 / 2 ;-5)$ & \\
\hline$(30,1 / 2 ; 10)$ & & $(-20,1 / 2 ;-10)$ & \\
\hline$(30,1 / 2 ; 20)$ & & & \\
\hline$\left(20, \frac{1}{8} ; 0\right)$ & $(20,1 / 80)$ & $(-20,1 / 80)$ & $(-20,1 / 80)$ \\
\hline$(20,1 / 85)$ & $(20,1 / 85)$ & $(-20,1 / 8-5)$ & $(-20,1 / 8-5)$ \\
\hline$(20,2 / 8 ; 0)$ & $(20,2 / 80)$ & $(-20,2 / 80)$ & $(-20,2 / 80)$ \\
\hline$(20,3 / 8 ; 0)$ & $(20,3 / 8 ; 0)$ & $(-20,3 / 8 ; 0)$ & $(-20,3 / 8 ; 0)$ \\
\hline$(20,5 / 8 ; 0)$ & $(20,5 / 8 ; 0)$ & $(-20,5 / 8 ; 0)$ & $(-20,5 / 8 ; 0)$ \\
\hline$(20, \% ; 0)$ & $(20, \% ; 0)$ & $\left(-20, \% \frac{6}{8} ; 0\right)$ & $(-20,6 / 8 ; 0)$ \\
\hline$(20,7 / 8 ; 0)$ & $(20,7 / 8 ; 0)$ & $(-20,7 / 8 ; 0)$ & $(-20,7 / 8 ; 0)$ \\
\hline$(20,7 / 8 ; 5)$ & $(20,7 / 8 ; 5)$ & $(-20,7 / 8 ;-5)$ & $(-20,7 / 8 ;-5)$ \\
\hline
\end{tabular}

The choice tasks for losses are not identical in absolute value to the ones for risk. In particular, the lowest value only reaches -20 instead of the 30 for gains. This was motivated by budget constraints. Inserting one or two prospects with a maximum loss of $€ 30$ PPP would have forced us to give an endowment of $€ 30$ PPP for the whole loss part, which would have considerably raised the costs of the experiment. 


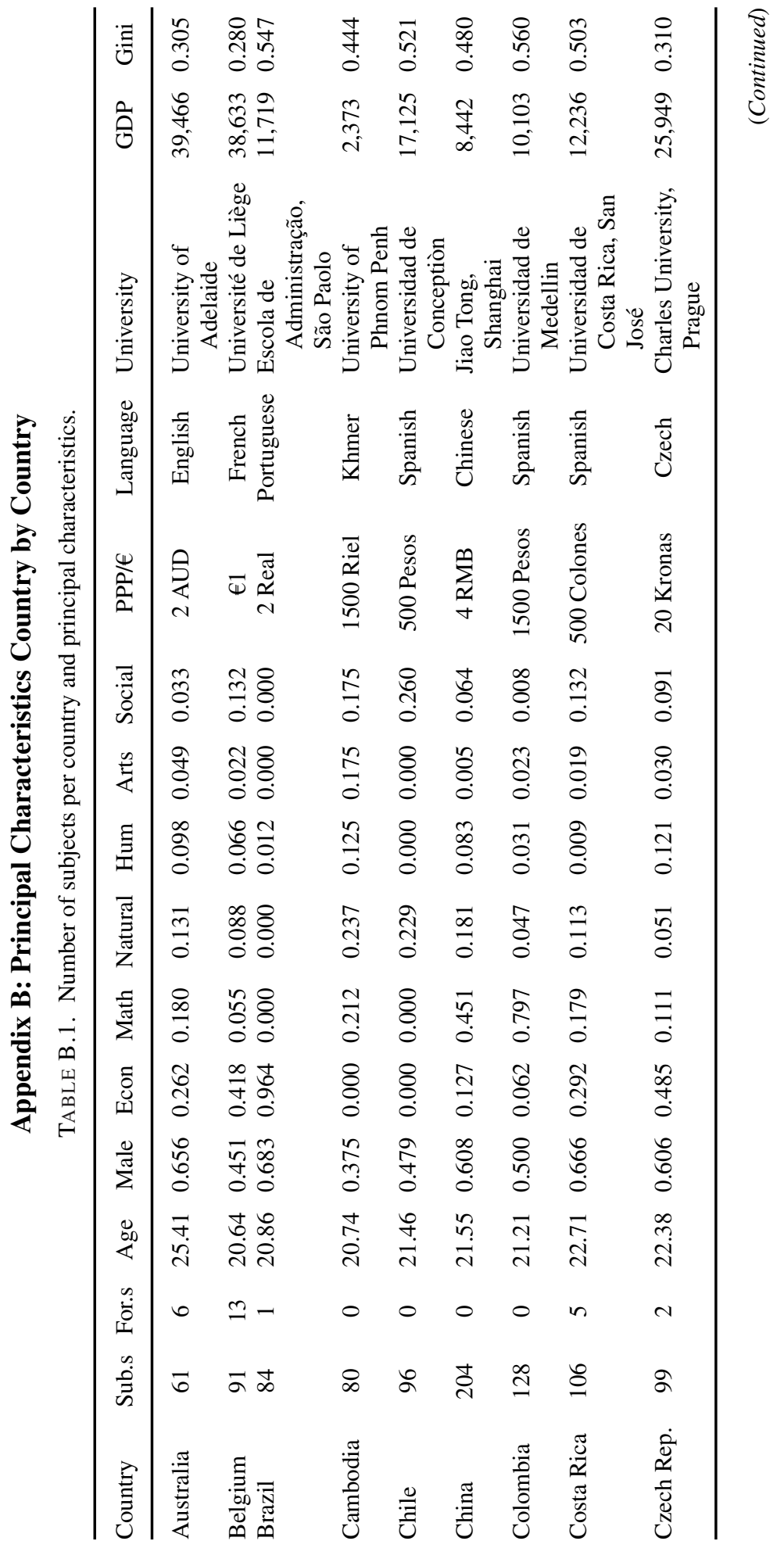




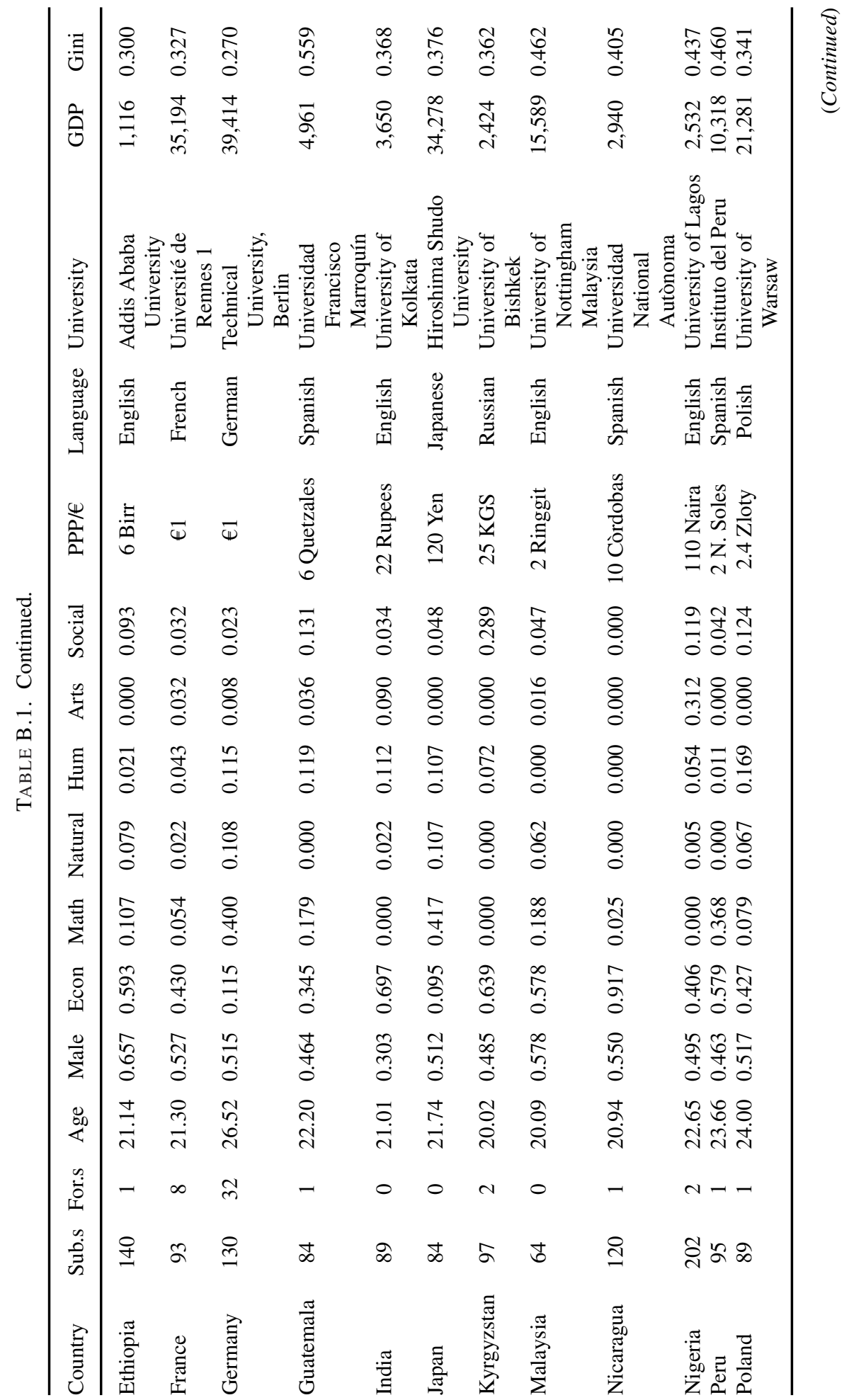




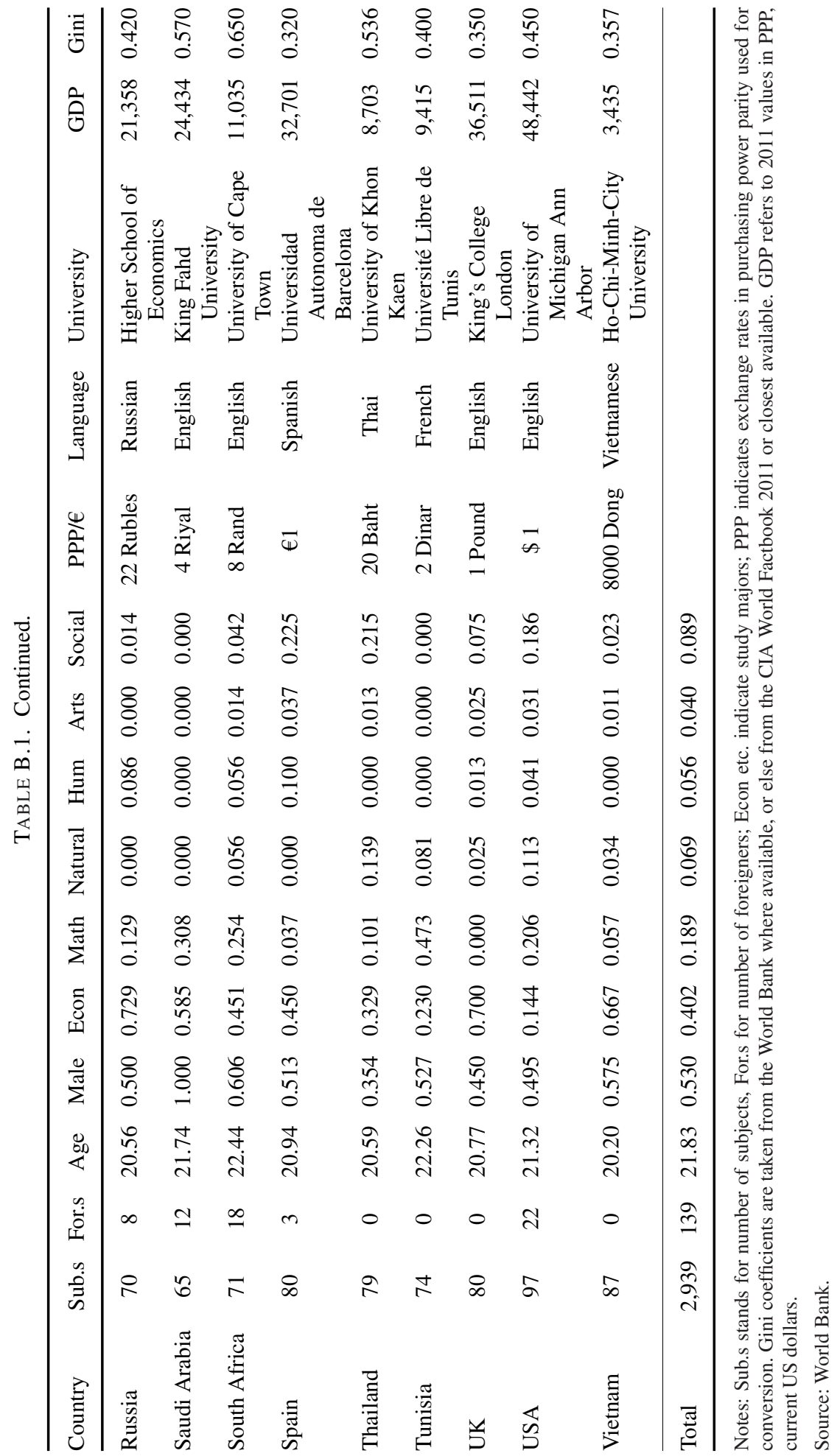




\section{References}

Abdellaoui, Mohammed (2000). "Parameter-Free Elicitation of Utility and Probability Weighting Functions."Management Science, 46, 1497-1512.

Abdellaoui, Mohammed, Aurélien Baillon, LÃætitia Placido, and Peter P. Wakker (2011). "The Rich Domain of Uncertainty: Source Functions and Their Experimental Implementation."American Economic Review, 101(2), 695-723.

Abdellaoui, Mohammed, Frank Vossmann, and Martin Weber (2005). "Choice-Based Elicitation and Decomposition of Decision Weights for Gains and Losses Under Uncertainty."Management Science, 51, 1384-1399.

Baltussen, Guido, Thierry Post, Martijn J. van den Assem, and Peter P. Wakker (2012). "Random Incentive Systems in a Dynamic Choice Experiment."Experimental Economics, 15, 418443.

Barseghyan, Levon, Francesca Molinari, Ted O’Donoghue, and Joshua C. Teitelbaum (2013). "The Nature of Risk Preferences: Evidence from Insurance Choices."American Economic Review, 103(6), 2499-2529.

Binswanger, Hans P. (1980). "Attitudes toward Risk: Experimental Measurement in Rural India."American Journal of Agricultural Economics, 62, 395-407.

Brislin, Richard W. (1970). "Back-Translation for Cross-Cultural Research.”Journal of CrossCultural Psychology, 1, 185-216.

Bruhin, Adrian, Helga Fehr-Duda, and Thomas Epper (2010). "Risk and Rationality: Uncovering Heterogeneity in Probability Distortion."Econometrica, 78, 1375-1412.

Cohen, Michele, Jean-Yves Jaffray, and Tanios Said (1987). "Experimental Comparison of Individual Behavior under Risk and Uncertainty for Gains and for Losses."Organizational Behavior and Human Decision Processes, 39, 1-22.

Croson, Rachel and Uri Gneezy (2009). "Gender Differences in Preferences."Journal of Economic Literature, 47, 1-27.

Cubitt, Robin P., Chris Starmer, and Robert Sugden (1998). "On the Validity of Random Lottery Incentive Systems." Experimental Economics, 1, 115-131.

Cubitt, Robin P., Chris Starmer, and Robert Sugden (2001). "Discovered Preferences and the Experimental Evidence of Violations of Expected Utility Theory."Journal of Economic Methodology, 8, 385-414.

Dimmock, Stephen G., Roy Kouwenberg, and Peter P. Wakker (2014). "Ambiguity Attitudes in a Large Representative Sample: Measurement and an Application to the Non-Participation Puzzle." Working paper, Erasmus School of Economics.

Dohmen, Thomas, Armin Falk, David Huffman, and Uwe Sunde (2010). "Are Risk Aversion and Impatience Related to Cognitive Ability?"American Economic Review, 100(3), 1238-1260.

Dohmen, Thomas, Armin Falk, David Huffman, and Uwe Sunde (2011a). "The Intergenerational Transmission of Risk and Trust Attitudes."Review of Economic Studies, 79, 645677.

Dohmen, Thomas, Armin Falk, David Huffman, Uwe Sunde, Jurgen Schupp, and Gert G. Wagner (2011b). "Individual Risk Attitudes: Measurement, Determinants, And Behavioral Consequences." Journal of the European Economic Association, 9, 522-550.

Donkers, Bas, Bertrand Melenberg, and Arthur Van Soest (2001). "Estimating Risk Attitudes Using Lotteries: A Large Sample Approach.”Journal of Risk and Uncertainty, 22, 165-195.

Einav, Liran, Amy Finkelstein, Iuliana Pascu, and Mark R. Cullen (2012). "How General are Risk Preferences? Choices Under Uncertainty in Different Domains."American Economic Review, 102(6), 1-36.

Ellsberg, Daniel (1961). "Risk, Ambiguity and the Savage Axioms." Quarterly Journal of Economics, 75, 643-669.

Etchart-Vincent, Nathalie and Olivier L'Haridon (2011). "Monetary Incentives in the Loss Domain and Behavior toward Risk: An Experimental Comparison of Three Reward Schemes Inclusing Real Losses." Journal of Risk and Uncertainty, 42, 61-83. 
Fehr-Duda, Helga and Thomas Epper (2012). "Probability and Risk: Foundations and Economic Implications of Probability-Dependent Risk Preferences."Annual Review of Economics, 4, 567593.

Friedman, Milton (1953). "Choice, Chance, and the Personal Distribution of Income." Journal of Political Economy, 61, 277-290.

Galor, Oded and Stelios Michalopoulos (2012). "Evolution and the Growth Process: Natural Selection of Entrepreneurial Traits."Journal of Economic Theory, 147, 759-780.

Hopland, Arnt O., Egil Matsen, and Bjarne Strom (2013). “Income and Choice Under Risk.” Working Paper No. 14313, Department of Economics, Norwegian University of Science and Technology, URL http://ideas.repec.org/p/nst/samfok/14313.html.

Kachelmeier, Steven J. and Mohamed Shehata (1992). "Examining Risk Preferences under High Monetary Incentives: Experimental Evidence from the People's Republic of China."American Economic Review, 82(5), 1120-1141.

Kahneman, Daniel and Amos Tversky (1979). "Prospect Theory: An Analysis of Decision under Risk."Econometrica, 47, 263-291.

Kanbur, S. M. (1979). "Of Risk Taking and the Personal Distribution of Income.”Journal of Political Economy, 87, 769-797.

Knight, Frank (1921). Risk, Uncertainty, and Profit. University of Chicago Press.

Lefebvre, Mathieu, Ferdinand M. Vieider, and Marie Claire Villeval (2010). "Incentive Effects on Risk Attitude in Small Probability Prospects."Economics Letters, 119, 115-120.

L'Haridon, Olivier, Peter Martinsson, and Ferdinand M. Vieider (2013). "All Over the Map: Heterogeneity of Risk Preferences Across Individuals, Contexts, and Countries." Working paper, WZB.

Plott, Charles R. (1996). "Rational Individual Behavior in Markets and Social Choice Process: the Discovered Preference Hypothesis." In The Rational Foundations of Economic Behavior, edited by Kenneth J Arrow, Enrico Colombatto, Marc Perlman, and Christian Schmidt, Proceedings of the IEA Conference held in Turin, Italy. Martins Press.

Rieger, Marc Olivier, Mei Wang, and Thorsten Hens (2014). "Risk Preferences Around the World."Management Science. Forthcoming.

Schoemaker, Paul J.H. (1990). "Are Risk-Attitudes Related across Domains and Response Modes?"Management Science, 36, 1451-1463.

Slovic, Paul (1995). “The Construction of Preference."American Psychologist, 50, 364-371.

Trautmann, Stefan T. and Richard J. Zeckhauser (2013). "Shunning Uncertainty: The Neglect of Learning Opportunities."Games and Economic Behavior, 79, 44-55.

van de Kuilen, Gijs (2007). "Subjective Probability Weighting and the Discovered Preference Hypothesis."Theory and Decision, 67, 1-22.

Vieider, Ferdinand M. (2012). "Moderate Stake Variations for Risk and Uncertainty, Gains and Losses: Methodological Implications for Comparative Studies."Economics Letters, 117, 718721.

Vieider, Ferdinand M., Thorsten Chmura, Tylor Fisher, Takao Kusakawa, Peter Martinsson, Frauke Mattison Thompson, and Adewara Sunday (2014). "Within- versus Between-Country Differences in Risk Attitudes: Implications for Cultural Comparisons."Theory and Decision. Forthcoming.

Vieider, Ferdinand M., Thorsten Chmura, and Peter Martinsson (2012). "Risk Attitudes, Development, and Growth. Macroeconomic Evidence from Experiments in 30 Countries." Working paper, WZB.

Vieider, Ferdinand M., Nghi Truong, Peter Martinsson, and Nam Pham Khanh (2013). "Risk Preferences and Development Revisited." Working paper, WZB.

von Gaudecker, Hans-Martin, Arthur van Soest, and Erik Wengström (2011). "Heterogeneity in Risky Choice Behaviour in a Broad Population.”American Economic Review, 101(2), 664-694.

Wakker, Peter (1994). "Separating Marginal Utility and Probabilistic Risk Aversion."Theory and Decision, 36(1), 1-44.

Weber, Elke U., Ann-Renee Blais, and Nancy E. Betz (2002). "A Domain-Specific Risk-Attitude Scale: Measuring Risk Perceptions and Risk Behaviors."Journal of Behavioral Decision Making, $15,263-290$. 
Wu, George and Richard Gonzalez (1999). "Nonlinear Decision Weights in Choice under Uncertainty."Management Science, 45, 74-85.

\section{Supporting Information}

Additional Supporting Information may be found in the online version of this article at the publisher's website:

Online Appendix to "Common Components of Risk and Uncertainty Attitudes Across Contexts and Domains" 